\title{
AN INITIAL EXAMINATION OF SUSTAINABLE LEADERSHIP AND EMPLOYEE ENGAGEMENT WITHIN EXTENSION NUTRITION PROGRAMS
}

\author{
A Dissertation \\ Presented to \\ the Faculty of the Graduate School \\ at the University of Missouri \\ In Partial Fulfillment \\ of the Requirements for the Degree \\ Doctor of Educational Leadership and Policy Analysis \\ by \\ Rachel L. Gordon-Poff \\ Dr. Barbara N. Martin, Dissertation Supervisor
}

May 2017 
The undersigned, appointed by the dean of the Graduate School, have examined the dissertation entitled

\section{AN INITIAL EXAMINATION OF SUSTAINABLE LEADERSHIP AND EMPLOYEE ENGAGEMENT WITHIN EXTENSION NUTRITION PROGRAMS}

presented by Rachel L Gordon-Poff, a candidate for the degree of doctor of education and hereby certify, in their opinion, it is worthy of acceptance.

Dr. Barbara N. Martin

Dr. Sandy Hutchinson

Dr. Doug Thomas

Dr. Carolyn P. McKnight 


\section{ACKNOWLEDGEMENTS}

I owe an incredible thank you to Dr. Barbara Martin for providing support and encouragement while I navigated the doctoral degree and the dissertation. She demonstrated incredible patience through this process. Additionally, I'd like to thank my entire dissertation committee, Dr. Sandy Hutchinson, Dr. Doug Thomas, and Dr. Carolyn McKnight, for their feedback and encouragement during the writing and research process.

This dissertation would not have been possible without the support of the University of Missouri Extension. To my colleagues who readily volunteered to let me interview them and discover their leadership practices, it is you who made this truly possible. Also, to the paraprofessional educators who completed the survey. Without their participation, the study would not have been possible.

A very special thank you goes to my husband who has demonstrated incredible patience, support, and understanding through this entire process. 


\section{TABLE OF CONTENTS}

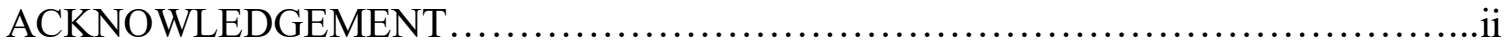

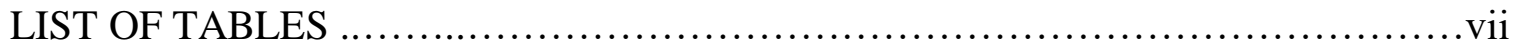

ABSTRACT .........................................................................ii

Section

1. INTRODUCTION TO DISSERTATION-IN-PRACTICE.......................1

Background......................................................

Statement of the Problem............................................... 4

Purpose of the Study ................................................ 6

Research Questions...............................................

Conceptual/Theoretical Framework..................................... 8

Sustainable Leadership ...................................... 8

Employee Engagement ......................................11

Design of the Study ............................................... 14

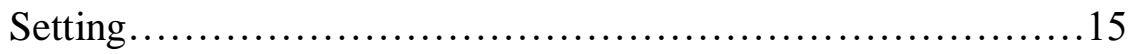

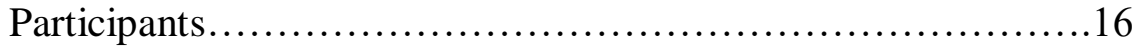

Data Collection............................................. 17

Data Analysis................................................. 19

Limitations and Assumptions........................................21

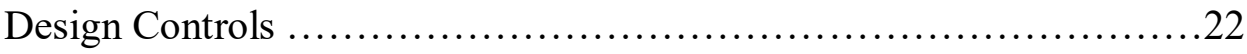

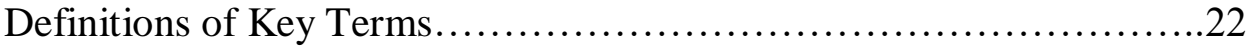

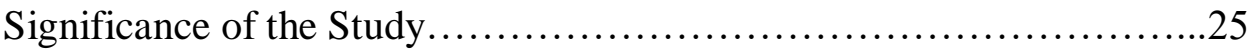

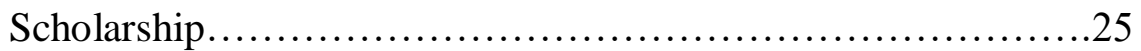

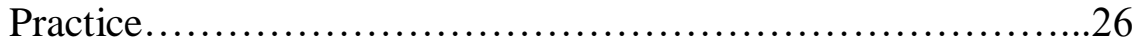

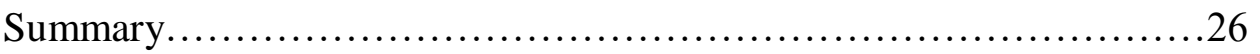




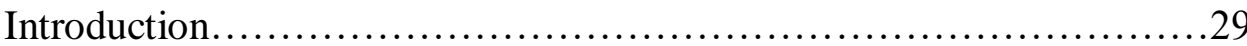

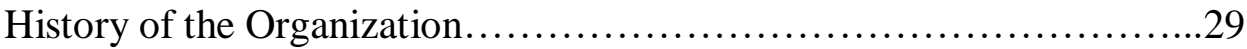

Organizational Analysis.................................................. 30

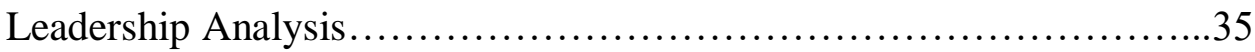

Implications for Research in the Practitioner Setting....................37

Summary ..........................................................

3. SCHOLARLY REVIEW FOR THE STUDY ..............................40

Introduction.................................................... 41

Leadership as a Theoretical Framework.......................42

Sustainable Leadership as a Conceptual Framework..............46

Employee Engagement as a Theoretical Framework..............49

Kahn's Theory of Engagement as a Conceptual Framework......52

Available Literature..............................................56

Leadership and Paraprofessionals...........................56

Employee Engagement.....................................59

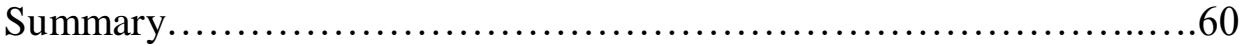

4. CONTRIBUTION TO PRACTICE.......................................62

Introduction......................................................... 63

Research Questions.......................................65

Conceptual/Theoretical Framework.....................................66

Sustainable Leadership......................................66

Employee Engagement....................................68

Methods........................................................... 70 


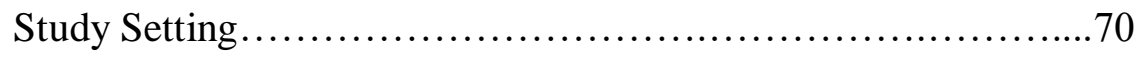

Study Participants........................................... 71

Data Collection............................................ 71

Data Analysis............................................... 73

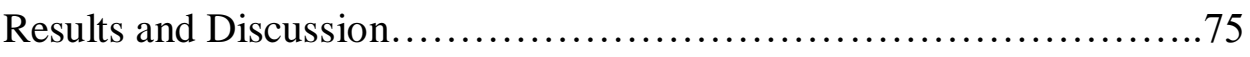

Research Question One.....................................75

Research Question Two....................................... 82

Research Question Three....................................... 83

Research Question Four.......................................... 84

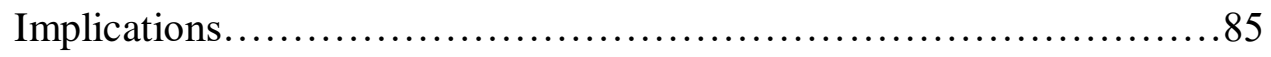

Recommendations....................................................... 87

Limitations and Direction for Future Research........................89

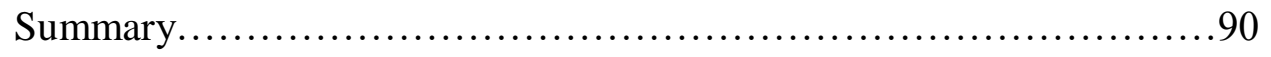

5. CONTRIBUTION TO SCHOLARSHIP.................................99

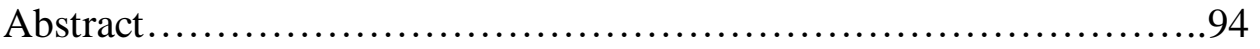

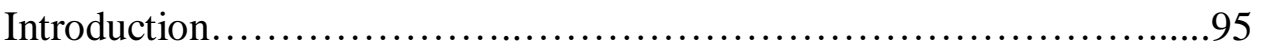

Research Questions..........................................96

Conceptual/Theoretical Framework...................................97

Sustainable Leadership.........................................99

Employee Engagement......................................97

Methods.......................................................... 98

Study Setting $\ldots \ldots \ldots \ldots \ldots \ldots \ldots \ldots \ldots \ldots \ldots \ldots \ldots \ldots \ldots \ldots \ldots$

Study Participants........................................98

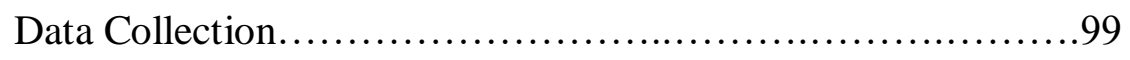

Data Analysis............................................ 100 
Results and Discussion......................................... 102

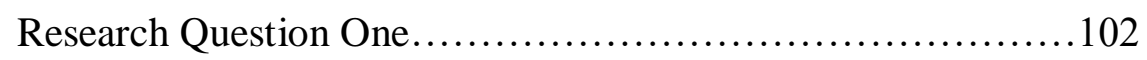

Research Question Two.................................109

Research Question Three....................................110

Research Question Four................................111

Implications for Research and Practice.......................... 112

6. SCHOLARLY PRACTITIONER REFLECTION....................... 117

REFERENCES........................................................ 122

APPENDIX A......................................................... 128

APPENDIX B......................................................... 134

APPENDIX C......................................................... 140

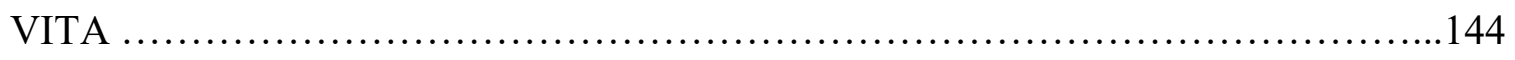




\section{LIST OF TABLES}

Table

Page

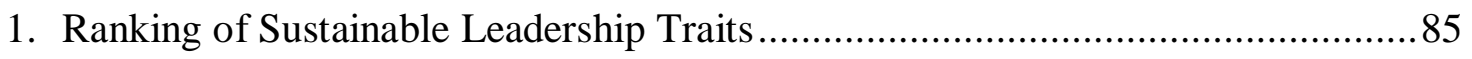

2. Ranking of Sustainable Leadership Traits (from Employee Survey) ...................86

3. Average UWES Scores................................................................... 92

4. Scatterplot of UWES and Sustainable Leadership Average Scores.......................94 


\begin{abstract}
Nutrition programs operated by Cooperative Extension organizations seek to provide nutrition education to a low-income audience nationally. There is research on the effectiveness of these programs, but gaps exist on the role of the leader and how their practices impact the educators and the programs as a whole. A transformative mixed-methods approach was used to capture both quantitative and qualitative data through a theoretical lens. Sustainable leadership and employee engagement were used as conceptual frameworks. Open-ended interviews with twelve leaders of Extension nutrition programs were conducted. An online survey was distributed to 100 nutrition educators to determine their perceptions of their leaders' sustainable leadership practices and also a personal employee engagement inventory, with a $63 \%$ return rate. The analysis of these interviews and surveys found that both the leaders and the educators reported the use of sustainable leadership practices by program leaders.

The qualitative portion of the study revealed six of the seven leadership traits were described by the leaders during their interviews. Also, there was no significant relationship between the reported levels of sustainable leadership practices by the leaders and the educators. From the employee engagement inventory, the educators of averaged an average level of employee engagement. Lastly, there was a significant positive relationship between the use of sustainable leadership and educator employee engagement. The use of sustainable leadership and the relationship between employee engagement can have implications for these programs nationally. This and future research on leadership and its impact on employee engagement can help inform policy and practice within national nutrition programs.
\end{abstract}


SECTION ONE

INTRODUCTION TO DISSERTATION-IN-PRACTICE 


\section{Introduction to the Background of the Study}

Cooperative Extension organizations in all 50 states and United States territories implement nutrition education through two national programs, SNAP-Ed (Supplemental Nutrition Education Program Education) and EFNEP (Expanded Food and Nutrition Education Program). These programs were created under the Smith-Lever Act, in conjunction with Cooperative Extension programs, to increase healthy eating habits and physical activity in low-income citizens ("The History of SNAP," 2015; United States Department of Agriculture, 2013). In addition, they provide education on nutrition and physical activity in schools, food pantries, homeless shelters, and other organizations serving low-income audiences. SNAP-Ed and EFNEP nationally employ paraprofessional educators to provide the program's education ("The History of SNAP" ; United States Department of Agriculture).

SNAP-Ed and EFNEP operate within Cooperative Extension units of land-grant universities. These institutions' missions are focused on connecting research from campus to the residents of their state. Because of the funding provided by the United States Department of Agriculture, SNAP-Ed and EFNEP are able to carry out the mission in the fields of nutrition and physical activity ("The History of SNAP," 2015; United States Department of Agriculture, 2013). Each state operates their program slightly differently based on the structure of the Extension organization. However, all states have paraprofessional educators who are hired from within the populations they are serving, and leaders who supervise them and the programs. Significant difference is within the roles of the leaders including how many paraprofessional educators they supervise, how 
large of a region they preside over, and what other duties they also have within the organization ("The History of SNAP"; United States Department of Agriculture).

The University of Missouri was established as a land-grant university through the Morrill Act of 1862, which provided state universities the ability to educate citizens in the fields of agriculture, home economics, and others ("Morrill Act," 2016). The Family Nutrition Education Programs (FNEP) through the University of Missouri Extension was established in 1969 (“History of MU Extension,” 2013). Consequently, Missouri operates a SNAP-Ed and EFNEP program simultaneously. Since 1969, this program has grown immensely in the state of Missouri to include 100 paraprofessional educators in almost all of the state's 114 counties and St. Louis city. Each of FNEP's eight administrative regions has a separate management team, consisting of a project director and program manager.

Because of the vast understanding of the program, oftentimes the expectation for how to lead and manage is a priority, with the emphasis remaining on program content, not leadership capacity. Instead, the programs main focus is on state standardization for program content, policies, and procedures. As the program continues to focus on policy, individual leaders can continue to lead in whatever approach they prefer. Currently, the focus is on paraprofessional educator performance and standardization of competencies, while none has gone into standardization among those who lead them. The fundamental understanding of how standards can regulate performance among paraprofessional educators has not been extended to leaders, thus allowing inconsistencies in leadership practices to potentially develop. Because no regulation occurs, FNEP at the University of 
Missouri Extension is unaware of what leadership practices are being used and what impacts those have on the paraprofessional educators they take so much effort to regulate.

\section{Statement of the Problem}

University Extension nutrition programs are far-reaching programs, with federal guidance dictating program direction and acceptable activities ("The History of SNAP," 2015; United States Department of Agriculture, 2013). These national standards provide some opportunity for flexibility for individual programs, but program priorities and focus areas follow the expected practice guidelines. National programs such as these thrive from standardization; it helps fundees communicate program value, with funders ensured their dollars are being used appropriately. These standards continue down to paraprofessional educators in the form of educator "Core Competencies" ("Core Competencies- EFNEP \& SNAP-Ed," 2015). These competencies include expectations for teaching, reporting, and personal accountability. Furthermore, these programs import the value of standardization among programs both between and within states ("Core Competencies- EFNEP \& SNAP-Ed"). The existence of these competencies ensures these programs, including the paraprofessional educators, are standard in program and values. Utilizing the same rationale and philosophy as was used during the creation of paraprofessional educator core competencies, the existence of standards or core competencies for program leadership would also create standardization and clarity of roles among programs and in the case of Missouri, the local program coordinators serve as direct supervisors to the paraprofessional educators.

The reality of extension nutrition programs nationally is no standards exist for leaders who supervise paraprofessionals in these organizations. Analysis and 
consideration have gone into what is expected of paraprofessional educators, but not to those who lead them (“Core Competencies- EFNEP \& SNAP-Ed,” 2015). The consequences of this lack of standardization of leadership expectation can result in discrepancies in how leaders interpret their roles, because there are no overarching and guiding leadership principles in which to follow. However, research reveals how leadership practices in paraprofessional nutrition programs have been found to correlate to the following employee outcomes: job satisfaction, motivation, retention, and performance (Dickin, Dollahite, \& Habicht, 2009; Dickin, Dollahite, \& Habicht, 2011; Okello \& Gibson, 2015).

Furthermore, the consequences of not having standardization among programs can be detrimental to employees and to program outcomes (Dickin, Dollahite, \& Habicht, 2010). The success and continuation of these programs are largely dependent on the individuals within the program and their ability to carry out the prescribed duties. For administrators, while the functions of the position are defined (approve expenses, manage budgets, observe nutrition programs, and evaluate paraprofessional performance), what is not explicit are the competencies or leadership practices that dictate the overall culture of the units. When these leadership standards do not exist or are not prescribed, vast differences are allowed to flourish. The existing research (Dickin, Dollahite, \& Habicht) on leadership and paraprofessional nutrition educators has established a positive relationship between leadership practices and employee outcomes, such as retention and job satisfaction. The reverse is also true; these unaddressed areas are the challenges, whereby, program coordinators can create issues such as employee disengagement, job dissatisfaction, and high turnover. Because research has identified a relationship between 
employee engagement and employee outcomes (Crawford, Le Pine, \& Rich, 2010; Harter, Schmidt, \& Hayes, 2002; May et al., 2004; Van den Broeck et al., 2008), employee engagement is used as the variable to conceptualize employee-level data.

\section{Purpose of the Study}

The purpose of this research study was to determine which sustainable leadership practices program coordinators within SNAP-Ed and EFNEP nutrition programs are using to manage and lead paraprofessional educators and to determine the level of engagement nutrition paraprofessional educators are experiencing within the workforce. Employee engagement is being utilized as the variable to evaluate the impact these practices have on paraprofessional educators (Kahn, 1990). Employee engagement was chosen because it is highly researched and has connections to many employee outcomes including job enrichment, work-role fit, and productivity (Harter, Schmidt, \& Hayes, 2002; May, Gibson, \& Harter, 2004). Additionally, this study sought to understand if a connection exists between the use of sustainable leadership practices and employee engagement. Galpin and Whittington (2012) explained, "at the core of the sustainability leadership model is an engaged workforce. Workforce engagement is a central element of transforming a firm's sustainability mission" (p. 41). This connection between sustainable leadership and engaged employees is important as this research seeks to find a similar connection in community nutrition programs.

Similarly, this study sought to fill a gap in the existing research on Extension nutrition programs. Literature of these programs covers many areas: the paraprofessional educators, program effectiveness, and even the type of information collected from the participants (Dickin, Dollahite, \& Habict, 2010; Dickin, Dollahite, \& Habict, 2011; 
Okello \& Gibson, 2015). A gap exists in the literature, however, in a significant study of the leaders, what practices they use, and how they impact the paraprofessional educators and the program. The available literature establishes a relationship between managerial practices and employee outcomes (Dickin, Dollahite, \& Habicht, 2009), but not enough to understand specifically what practices are used and how to replicate them.

The University of Missouri Extension's Family Nutrition Education Programs were used as the setting to complete this examination of the presented study. Similar programs exist nationwide, the University of Missouri were used because the researcher had access to conduct the study at this location. The program is divided into eight geographic regions and they were each studied so the data could be examined as a whole and separated by geographic region. These results could be utilized nationally and by other Extension nutrition programs. The federal funding level for 2016 was $\$ 408$ Million dollars for all of the SNAP-Ed programs nationally. This funding is historically controversial because of its large number as well as because it is a part of the larger SNAP budget ("The History of SNAP," 2015; United States Department of Agriculture, 2013). The research could guide policy and programmatic changes to potentially increase the retention and satisfaction of the workforce, continuing to benefit the program as a whole. In order to guide this study, the researcher proposed a host of questions to inform the study's constructs: sustainable leadership and employee engagement.

\section{Research Questions}

The research questions guiding this study are:

1. Do the leadership practices of program administrators within the University of Missouri Extension align with Sustainable Leadership principles? 
2. Is there a difference between the program administrators within the University of Missouri Extension's reported sustainable leadership practices and the paraprofessional educators' perceptions of their administrators' sustainable leadership practices?

3. What is the reported level of employee engagement of nutrition paraprofessional educators within the University of Missouri Extension nutrition programs?

4. Is there a relationship between the level of sustainable leadership practices used by program administrators and employee engagement scores of nutrition paraprofessional educators?

\section{Conceptual/Theoretical Framework}

In order to fully realize and provide the framework necessary to understand this study and its meaningfulness, two separate frameworks are presented: sustainable leadership (Hargreaves \& Fink, 2006) and employee engagement (Kahn, 1990). These two theories are used to provide context and theoretical understanding to two distinct facets of community nutrition programs: the leaders and the paraprofessional educators. The first is focused on the leader's role in the mutual relationship of leader and paraprofessional educator by framing it within a leadership theory. Then, the paraprofessional educator's side is framed by the use of employee engagement theories. These two frameworks are presented here.

\section{Sustainable Leadership}

The theoretical framework of leadership provides a guide for understanding how leaders' practices can impact those they manage, as well as the programs they coordinate. 
Three leadership theories were considered for use as the conceptual framework: authentic (Walumbwa et al., 2008), team (Hill, 1982), and sustainable leadership theories (Hargreaves \& Fink, 2004). Authentic leadership focuses on the genuine nature or authenticity of the leader. Authentic leaders must excel at self-regulatory practices and use an internal moral compass to guide actions and decision-making (Walumbwa et al.). The next leadership theory considered was team leadership. Team leadership's primary principles state the function of the leader is for monitoring the team and ensuring team effectiveness (Hill). While, sustainable leadership values the importance of both deep and broad learning, and making decisions and changes to impact the greater good both in the present and for the future (Hargreaves \& Fink).

In order to arrive at one leadership theory, two had to be eliminated. Authentic leadership was eliminated because it is more about the individual characteristics of the leader as opposed to the practices or strategies they implement (Northouse, 2013). The next theory, team leadership (Hill, 1982) was not chosen for use as the conceptual framework because although Extension nutrition programs employ many people who work toward a collective goal, all team members work independently and do not collaborate regularly. For the purpose of this study, sustainable leadership will be used to provide understanding and analysis of the leaders' behaviors because it identified seven distinct principles; these principles can be easily understood, researched, and applied to the nutrition program leaders. It was also the only theory to emphasize diversity or longevity (Northouse).

Hargreaves and Fink (2006) introduced seven principles of sustainable leadership. The seven principles of sustainable leadership are depth, length, breadth, justice, 
diversity, resourcefulness, and conservation (Hargreaves \& Fink). These seven principles interacting together is what provides uniqueness to this theory. At the core of an engaged workforce is the sustainable leader (Galpin \& Whittington, 2012).

The first sustainable leadership principle is depth. This principle focuses on two elements of leadership for learning: deep and broad learning and slow knowing. Deep and broad learning is a multi-faceted approach to learning, "is learning for meaning, learning for understanding, learning for life" (Hargreaves \& Fink, 2006, p. 33). Length, the second principle, is the ability to successfully transition from one leader to another while not depending entirely on the succession plan. Breadth builds upon the previous two principles. Success between leaders can also depend on the breadth of the knowledge spread. It can be essential during leadership transitions.

The first three principles together can create great leaders, but these leaders should also be aware of the needs of all in order to ensure justice and fairness. This requires leadership to extend beyond the immediate environment and have a vision aligned with the overall good, which is the fourth principle of justice (Hargreaves \& Fink, 2006). It is important in context of this theory because if leadership is to be long-lasting it also should have a moral compass, acting in the best interests of everyone. Further, is a focus on diversity. The ability for leadership to be sustainable, it should also embrace diversity. Diversity provides people the ability to adapt and learn in complex environments and learn from each other. These efforts must align with the overall mission as well as the policies and procedures (Hargreaves \& Fink).

Contributing to the theory is the concept of resourcefulness. Healthy organizations and leaders are aware of their existing resources and the finite nature of 
them. The final of the seven principles is conservation which supports a leader who is able to value the past while looking to the future. Many leadership theories ignore the importance of the past. Although it can be a source of resistance, it can also be a valuable resource of knowledge and history (Hargreaves \& Fink, 2006). The combination of these seven principles creates a complex and thorough understanding of sustainability and can be simply defined as "a sustainability leader is someone who inspires and supports action towards a better world" (Visser \& Courtice, 2011, p.3). The combination of these seven principles create environments to make decisions for organizations and programs based on the greater good while accounting for the past, being resourceful and, looking to the future.

\section{Employee Engagement}

The use of employee engagement as an additional conceptual framework helps ground the use of the leadership practices in an understanding of outcomes for nutrition paraprofessional educators. The three employee engagement theories considered for use are a job burnout perspective (Maslach, Schaufeli, \& Leiter. 2001), the job demandsresources (JD-R) model (Bakker \& Demerouti, 2007) and Kahn's (1990) theory of employee engagement. The job burnout perspective operationalizes employee engagement as the opposite of burnout as the basis for the theory (Maslach, Schaufeli, \& Leiter). The next presented theory JD-R very similarly views employee engagement as the opposite of burnout, but utilizes additional theory to provide explanation. The theory uses the lens of two factors, job demands and job resources, to explain burnout. Job demands are explained as the physical factors of work such as workload while job resources are at the organizational level such as compensation (Bakker \& Demerouti). 
The last presented theory is Kahn's theory of employee engagement. Kahn's theory views engagement as a psychological condition. He argued the extent to which employees are engaged or disengaged was due to how the psychological factors of meaningfulness, safety, and availability interacted with who they are and the roles they occupy.

In order to define one employee engagement theory, the burnout perspective and JD-R were both eliminated from consideration. The burnout perspective was eliminated because of its oversimplified understanding of engagement and burnout as the counter to each other (Saks \& Gruman, 2014) and JD-R because critics have argued it is more of a framework for understanding job demands and resources than a theory (Saks \& Gruman). Kahn's theory was chosen for the purpose of this study because it the most theoretically rich, examining the psychological aspects of employee engagement while the other two theories both operationalize engagement as the opposite of burnout.

In Kahn's (1990) theory of engagement, two constructs were presented: personal engagement and personal disengagement. Kahn defined personal engagement "as the harnessing of organization members' selves to their work roles; in engagement, people employ and express themselves physically, cognitively, and emotionally during role performances" (p. 694). Contrarily, Kahn defined personal disengagement "as the uncoupling of selves from work roles; in disengagement, people withdraw and defend themselves physically, cognitively, or emotionally during role performances” (p. 694). Kahn's theory of employee engagement examined personal engagement and personal disengagement through the lens of three psychological facets: psychological meaningfulness, psychological availability, and psychological safety. Other researchers 
believe Kahn's theory is a good way to conceptualize engagement without overlapping with burnout like many other employee engagement theories (Schaufeli, 2013) and the three psychological facets contribute to the rich theoretical understanding.

Kahn (1990) explained psychological meaningfulness as the feeling of receiving a return on self-investment of one's roles. These feelings are associated when individuals feel useful, valuable, and of individual worth. Furthermore, meaningfulness is associated with being appreciated and making a difference. Psychological safety is the ability for employees to feel safe and secure in their work by being able to be themselves without fear of negative consequences. This sense of safety is associated with trust in the ability to engage (Kahn). The ability for individuals to feel psychologically safe relies on interpersonal relationships, group dynamics, management style, and organizational norms. Interpersonal relationships and group dynamics both required positive and trusting relationships to exist, both on an individual and group level. When those exist, individuals are able to attempt new things without fear of failure and retribution. Much like the positive impact of interpersonal relationships, supportive management practices also contribute to safety. The final construct of psychological availability is the capacity to be able to personally engage in a given moment. "It measures how ready people are to engage, given the distractions they experience as members of social systems" (p. 714). Four facets can impact availability: physical energy, emotional energy, insecurity, and outside life. "Personal engagement demanded levels of physical energy, strength, and readiness that personal disengagement did not" (Kahn, p. 714). Emotional energy similarly is required for availability. Being engaged requires a level of emotional investment in order to meet the demands of engagement. Insecurity is also essential, "for 
individuals to express their selves in social systems, they must feel relatively secure" (Kahn, p. 715). The fourth facet of outside life is impacted because of its ability to create a psychological separation from their roles and their ability to engage (Kahn). Saks and Gruman (2014) explained, "Employees who experience a greater amount of psychological meaningfulness, safety, and availability will engage themselves to a greater extent in their work role" (p. 160).

\section{Design of the Study}

The design of the study used pragmatism as a worldview by which to guide the research study. The major concern of pragmatism is the application, and it "arises out of actions, situations, and consequences" (Cresswell, 2013, p.10). The fundamental underpinning of pragmatism lends itself to a mixed method research design because pragmatism is not steadfast to only one perspective or philosophy. A mixed method design was chosen to provide a better understanding of a problem than can be provided with only using either quantitative or qualitative approaches alone. More specifically, a procedure known as transformative mixed methods was used for this study.

Transformative mixed methods incorporate both qualitative and quantitative research through a theoretical lens (Cresswell). The quantitative and qualitative data collection occurred concurrently, which is consistent with the principles of this approach. Additionally, using mixed methods better helped the researcher triangulate the data and to balance the strengths of the quantitative and qualitative approaches against each other (Cresswell). The use of mixed methods provided the researcher to incorporate both inductive and deductive reasoning to provide a more complex understanding of the data collected. 


\section{Study Setting}

The setting used to answer the research questions was the eight geographic regions of the University of Missouri Extension's Family Nutrition Education Programs (FNEP). FNEP in Missouri is one of the federally funded programs for nutrition education. These programs exist within all 50 states and United States territories. The Missouri FNEP program has been operating for 46 years with EFNEP and 21 years with SNAP-Ed. These two programs run concurrently under the umbrella of FNEP.

Within Missouri FNEP, there are eight administrative regions, which are created geographically. They organize the state by counties. The smallest geographic regions having only three counties and the largest having 20 . There is also great variation in the number of paraprofessional educators; regions range from having 9 to 21 . In addition, the population density of the state varies greatly. The two smallest geographic regions have only three counties each but together account for approximately half of the population of Missouri. Each of the eight geographic regions has a two-person administrative unit, including a project director and program manager. The project director is the direct supervisor of the paraprofessional educators and serves in an administrative capacity. They are responsible for performance, personnel, budgets, and all administrative decision. The program manager serves in a program support function while having some leadership responsibilities. They are responsible for training, curriculum, and overall program support to FNEP.

In order to utilize the program for this research, the associate dean of the college of Human Environmental Sciences Extension at the University of Missouri consented to the scope of study and signed the gatekeeper consent form (Appendix A). Then, a 
proposal was submitted to the University of Missouri's Institutional Review Board (IRB).

Once IRB approval was received, data collection for the proposed study began.

\section{Study Participants}

In order to answer the research questions, two types of participants were recruited. The first are those in the leadership position; both project directors and program managers were identified and asked to participate in a qualitative interview. Seven of the eight administrative units were asked to participate, the researchers' region was excluded to avoid any potential conflicts. These interviews were conducted either in-person or via videoconference. This identification of administrators to participate is considered a purposeful sample (Merriam, 2009). A purposeful sample allowed the researcher to directly target participants who will contribute the best data to the study (Cresswell, 2013). The researcher contacted each personally by phone or email to ask for their participation in the study utilizing University of Missouri Extension public directories for contact information. Interviews were audiotaped. All but one leader agreed to participate, the sample size is seven project directors $(n=7)$ and five program managers $(n=5)$.

The second set of participants was current paraprofessional educators. An email listserv exists of all current paraprofessional educators employed at the University of Missouri Extension FNEP. This included 101 employees. The survey received 64 responses, a response rate of $63.4 \%$. This purposeful sampling was done for two reasons. The first was convenience; the researcher had easy access to conduct an online survey on all of these participants. Secondly, because of the structure of the organization, they all share the same job title and can easily be used to compare against their respective supervisors, who also all have the same job title (Creswell, 2013; Merriam, 2009). This 
is a natural place for comparison, as the organizational structure provides an established comparison point.

\section{Data Collection}

A mixed-method design was used in order to capture in-depth data from the leaders and to triangulate the data to the paraprofessional educators they manage (Creswell, 2013). Two distinct strategies for data collection were used. To collect data on what leadership practices are being used and if they relate to sustainable leadership principles, a qualitative interview was conducted with each leader. These semi-structured interviews lasted between 30-60 minutes and were conducted either in-person or via videoconference. All participants signed an informed consent (Appendix A). The questions asked were open-ended, asking each leader to reflect specifically on their general leadership philosophies and specific examples of their use of leadership practices (Appendix B). The interview had five distinct sections, the opening questions, introductory questions, transition questions, key questions, and ending questions (Merriam, 2009). The interview protocol was created to guide the interview session, which included an introduction, probes for the questions, and a thank you to the participant (Cresswell).

The second data collection was the use of an electronic survey sent to the current listserv of nutrition paraprofessional educators. Survey responses were anonymous; no identifying information was collected. The survey opened with an informed consent statement (Appendix A). It only asked the participants to identify in which of the eight geographic regions they work. The survey consisted of two parts. The first was an employee engagement inventory. The employee engagement inventory was the Utrecht 
Work Engagement Scale (UWES), which consists of 17 items to measure employee engagement (Appendix B). This is the most widely used Employee engagement survey; it has been tested for reliability and validity in its many uses in research studies (Schaufeli, Bakker, \& Salanova, 2006; Schaufeli \& Bakker, 2003). "The original UWES-17 has encouraging psychometric features for its scores. For instance, internal consistencies (Cronbach's alpha) typically range between .80 and .90 (Demerouti, Bakker, Janssen \& Schaufeli, 2001; Durán, Extremera, \&Rey, 2004; Montgomery, Peeters, Schaufeli, \& Den Ouden, 2003; Salanova, Schaufeli, Llorens, Peiró, \& Grau, 2001; Schaufeli \& Bakker, 2004). Thus, values of Cronbach's alpha exceed the value of .70 that is traditionally used as a rule of thumb (Nunnally \& Bernstein, 1994), and even more so, in almost all cases, alpha satisfies the more stringent value of .80 that is now considered a generally accepted standard (Henson, 2001)" (Schaufeli et al.). The UWES also is available without cost to use freely for non-commercial, scientific research. Additionally, the survey sent to paraprofessional educators included a series of questions determining their perception of their program administrators' use of the seven sustainable leadership practices (Appendix B). This second portion of the survey was created by the researcher to add an additional point of analysis in order to determine if leaders' reported practices are consistent with the paraprofessional educators' perceptions of these same practices. It consisted of seven questions on a Likert-type scale asking the paraprofessional educators' perceptions of the sustainable leadership practices utilized by their region's administrators. Each question had a short-answer follow-up allowing the paraprofessional educator to give an example of a time this behavior was either utilized or not. This survey was distributed via email using Qualtrics surveys web platform and 
using an internal listserv consisting of all paraprofessional educators within the University of Missouri Extension.

\section{Data Analysis}

The data analysis procedure was multi-step and addressed the four research questions.

Initially, the qualitative interviews were transcribed for ease of data analysis. The researcher then focused on coding by using Hargreaves and Fink's (2006) seven principles of sustainable leadership. Focused coding consists of line-by-line coding to identify themes (Emerson, Fretz, \& Shaw, 2011). The conceptual framework of sustainable leadership was used as the coding themes because it has already been established. Once the coding was complete, in order to conduct the later analyses, a numerical value was assigned to each of the eight administrative regions as well as an overall score for the entire program. Each administrative unit received a numerical score from 0 to 7 . For each of the seven sustainable leadership practices, one will be awarded for each of the seven practices the unit uses (could be either the project director or the program manager). For example, a unit identified both breadth and width as practices, received a score of 2 . Averaged scores ranged from 2 to 5 practices used per region. These seven scores were averaged to determine the average level of sustainable leadership practices across the entire program, with an average score of 3.6). Additionally, the paraprofessional educator responses to the 9-item questionnaire about their leaders' sustainable leadership practices was also used to provide information related to the research question. This first portion of the data analysis addresses the first 
research question, "Do the leadership practices of program administrators within the University of Missouri Extension align with Sustainable Leadership principles?”

The second research question, "Is there a difference between the program administrators within the University of Missouri Extension's reported sustainable leadership practices and the paraprofessional educators' perceptions of their administrators' sustainable leadership practices?" was answered by comparing two pieces of data using a t-test. A t-test was used because it is the preferred analysis for determining a correlation between two independent variables (McDavid, Huse, \& Hawthorn, 2013). The two numbers being compared are the numerical values assigned to the leaders' sustainable leadership practices and the average scores of the paraprofessional educator survey asking their perceptions of their leaders' sustainable leadership practices. In order to determine significance, alpha $<0.5$ which is considered a standard for stringent data analysis (McDavid, Huse, \& Hawthorn).

Then, the data collected from the paraprofessional educators was scored based on the Engagement Scale to determine employee engagement scores of each individual. Scores were calculated by adding all responses ( 1 to 6 ) and then dividing by the number of items (17) (Schaufeli, et al., 2006). Scores were averaged across all respondents and also amongst respondents from different geographic regions in order to provide a comparison point. Norm scores were used to determine levels of employee engagement $($ Mean $=3.74, \mathrm{SD}=1.17)$. Very low $(<1.78)$, Low (1.78-2.88), Average (2.89-4.66), High (4.67-5.50), Very High (>5.50) (Schaufeli, et. al). This answered the third research question, "What is the level of employee engagement of nutrition paraprofessional educators within the University of Missouri Extension nutrition programs?"” 
The average engagement score from each region underwent a t-test to determine correlation (alpha <.05) against the sustainable leadership score of each region to answer the final research question, "Is there a relationship between the use of Sustainable Leadership practices by program administrators and Employee engagement scores of nutrition paraprofessional educators?" A t-test was used because it is the preferred analysis for determining a correlation between two independent variables (McDavid, Huse, \& Hawthorn, 2013). Significance level was set at alpha <.05.

\section{Limitations and Assumptions}

There are several limitations to the study. First, there are many SNAP-Ed and EFNEP programs and they are all operated differently based on their administrative expectations and this study is only capturing data from one program at one state. It will be difficult to generalize results to additional Extension nutrition programs based on this initial study (Cresswell, 2013). These principles can potentially still be of use to other programs, but they would individually have to consider their own program and how it functions (Cresswell). Limitations to this study also include the personal connection to the organization due to the researcher's employment (Merriam, 2009). The researchers is a Project Director of one of the eight geographic regions being studied. This potential bias has helped dictate the approach the researcher is taking to this study. The researcher excluded her region entirely, neither the leaders were interviewed nor the paraprofessional educators were surveyed. Additional limitations exist because only quantitative data via surveys is being collected from the paraprofessional educators and only qualitative data being collected from the program leaders. Due to the geographic distance and large numbers of paraprofessional educators, the researcher is restricted to 
quantitative data from the paraprofessional educators and because of the small sample size, the researcher is restricted to only collecting qualitative data from the leaders.

\section{Design Controls}

The researcher utilized the following controls in order to reduce bias in the research conducted. To control for any potential bias related to the researcher's role within the organization, only seven of the eight FNEP units will be included. The researcher excluded her own unit from the inquiry because of any potential bias (Merriam, 2009). Also, in order to reduce bias, only open-ended questions were used in the interviews (Merriam). The use of open-ended questions was designed to elicit opinions and views of the participants without being skewed by the perspective of the researcher (Merriam). Then, the coding was done based on the established leadership principles to also help reduce bias. Design controls also existed at the paraprofessional level in the use of surveys. By adding opportunities for paraprofessional educators to leave short answer responses giving examples of the use of sustainable leadership practices, the researcher attempted to gather some data more descriptive or qualitative in nature to supplement the survey responses.

\section{Definitions of Key Terms}

Key terms were defined here in order to provide a deeper understanding of the constructs and their individual facets.

Core Competencies: A set of standards and expectations to regulate behavior for a specific group or profession.

Employee Engagement: “The harnessing of organization members' selves to their work roles; in engagement, people employ and express themselves physically, 
cognitively, and emotionally during role performances" (Kahn, 1990, p. 694). The three distinct facets of employee engagement are defined below.

Psychological Meaningfulness: Kahn (1990) explained psychological meaningfulness as the feeling of receiving a return on self-investment of one's roles.

Psychological Safety: Psychological safety is the ability for employees to feel safe and secure in their work by being able to be themselves without fear of negative consequences.

Psychological Availability: The final construct of psychological availability is the capacity to be able to personally engage in a given moment.

Land-grant University: “A land-grant college or university is an institution that has been designated by its state legislature or Congress to receive the benefits of the Morrill Acts of 1862, 1890, and 1994. . . To disseminate information gleaned from the experiment stations' research, the Smith-Lever Act of 1914 created a Cooperative Extension Service associated with each land-grant institution. This act authorized ongoing federal support for extension services" (“Land-Grant University FAQ," 2016).

Sustainable Leadership: "Sustainable educational leadership and improvement preserves and develops deep learning for all that spreads and lasts, in ways that do no harm to and indeed create positive benefit for others around us, now and in the future" (Hargreaves \& Fink, 2006, p. 17). The seven principles of sustainable leadership are defined here. 
Depth: The first Sustainable Leadership principle of depth is explained, 'Sustainable Leadership matters. It preserves, protects, and promotes deep and broad learning for all in relationships of care for others" (Hargreaves \& Fink, 2006, p. 23).

Length: The principle of Length focuses on how the ability to successfully transition from one leader to another does not depend entirely on the succession plan, but it contributes. Effective coordination and planning of leadership succession create the capacity for continued improvement.

Breadth: Success between leaders can also depend on the breadth of the knowledge spread. There are multiple patterns of distributing leadership, such as delegation, facilitated, and guided.

Justice: "Does no harm to and actively improves the surrounding environment by finding ways to share knowledge and resources with neighboring schools and the local community" (Hargreaves \& Fink, 2006, p. 142).

Diversity: Diversity must be a priority of all and be reflected not only in the action of the leader but the actions of the entire educational organization.

Resourcefulness: It is essential for a sustainable leader to be thoughtful about his or her use of resources and how it can impact the present, but also the future. 
Conservation: "Sustainable Leadership respects and builds on the past in its quest to create a better future" (Hargreaves \& Fink, 2006, p. 225).

\section{Significance of the Study}

There is little existing research drawing a connection between sustainable leadership practices within Extension nutrition programs and employee engagement levels. While research has specifically examined leadership practices within Extension nutrition programs (Dickin, Dollahite, \& Habicht, 2009; Dickin, Dollahite, \& Habicht, 2011; Okello \& Gibson, 2015) and employee engagement (Harter, Schmidt, \& Hayes, 2002; Kahn, 1990; May, Gilson, \& Harter, 2004). Because Extension nutrition programs are federally mandated and funded programs ("The History of SNAP," 2015; United States Department of Agriculture, 2013), there comes a certain level of responsibility and diligence essential to the implementation of these programs. The need for research on how leadership practices can impact employee engagement, and therefore employee outcomes such as satisfaction and turnover, can have ripples throughout the national implementation of these federally funded programs.

\section{Scholarship}

Extension nutrition programs have existed for over 45 years (United States Department of Agriculture, 2013). A large body of work exists but focuses almost entirely on program outcomes and participant behavior change. This research is essential to the continued success of the programs, but the facet of research on the leaders and paraprofessional educators' behaviors and outcomes can also impact the program (Dickin, Dollahite, \& Habicht, 2010). By adding to this body of knowledge, additional 
research can occur and continue to create a wealth of scholarship to impact policy at the state and national levels.

\section{Practice}

This research can have implications for the nutrition programs at the University of Missouri Extension and at other programs nationally. If this research can find a relationships between sustainable leadership practices and employee engagement within these programs, this current and future research can be used to inform future policy. If desirable employee outcomes can be correlated with leadership practices and philosophies, future training and management practices can be adapted. Continued research on desirable leadership practices could also help inform the creation of leadership "Core Competencies" (“Core Competencies- EFNEP \& SNAP-Ed,” 2015).

\section{Summary}

This section outlined the preliminary research plan to examine leadership practices and the perceived impacts on paraprofessional educators and programs. First, a background was presented, followed by the statement of the problem. Once the issue being studied was explained, a purpose of the study was articulated. The conceptual frameworks of sustainable leadership and employee engagement were discussed, followed by the study design. This preliminary research prospectus will serve as a guide for the researcher to begin answering the research questions provided. By understanding what practices are being used and how they are related to paraprofessional educators' perceptions is a potential first step in informing the creation of leadership standards or leadership core competencies. Section two of this proposal provides a history of the organization and program being researched. It also will deliver an analysis of the 
organization and of the leadership. The second section concludes with implications for research in the practitioner setting. The third section of the proposal is the scholarly review relevant to the study, conceptual and theoretical frameworks, and the research questions. Section four a summary report to be provided to the University of Missouri Extension for their understanding of the study and its outcomes. Additionally, section five is a submission-ready journal article for the Journal of Nutrition Education and Behavior. 
SECTION TWO

PRACTITIONER SETTING FOR THE STUDY 


\section{Introduction}

Section two of the dissertation-in-practice includes a history of the University of Missouri and more specifically, how a land-grant institution created a Cooperative Extension program. It also included an analysis of the organization as it relates to the research study. Next, the analysis will be focused on leadership. Finally, the implications for research in the practitioner setting will be explored. Then, the second section of the dissertation-in-practice will be summarized.

\section{History of the Organization}

The University of Missouri (MU) was founded in 1839. It was located in Columbia, MO after the local residents pledged $\$ 117,921$ to win the bid to place the new state University in Boone County. It was the first university west of the Mississippi River and the first university located in the land from the Louisiana Purchase ("History of the University of Missouri,” 2016). In 1870, MU enacted its status as Missouri's land-grant institution, a right afforded it under the Morrill Act of 1862 ("History," 2016). The establishment of the MU as a land-grant institution laid the foundation for the modernday University of Missouri Extension just as land-grant institutions nationwide would all become the homes of modern Extension services.

The later addition of the Smith-Lever Act of 1914 established land-grant institutions to take their research and knowledge and spread it through the rural residents of their state through a National Extension Service ("Smith-Lever Act of 1914," 2016). Because of the Smith-Lever Act of 1914, MU Extension, along with all other Cooperative Extension services, celebrated 100 years in 2014. Within Extension programs, the first community nutrition branch was created in 1969 to address concerns of nutrition and physical activity in low-income communities, specifically among those raising young 
children (United States Department of Agriculture, 2013). The program was called the Expanded Food and Nutrition Education Program (EFNEP). EFNEP employed paraprofessional educators from a low-income community to teach nutrition skills to parents raising children. The program historically targeted "homemakers" and EFNEP paraprofessional educators went into homes to teach nutrition and cooking skills. The programs have evolved and many programs, such as Missouri's, no longer do home visits, but still target the identified low-income caregiving population through agencies and organizations who serve the audience. EFNEP was created and funded by the United States Department of Agriculture and it expanded and currently operates in all 50 states, the District of Columbia, and the six United States territories. Additionally, a separate funding stream from the United States Department of Agriculture, in conjunction with the Supplemental Nutrition Assistance Program (SNAP), was created to provide nutrition education to those receiving the public assistance of SNAP, formerly known as Food Stamps. SNAP-Ed, as the new program was called, also operates in all 50 states and U.S. territories. The University of Missouri Extension has housed EFENP since 1969 and SNAP-Ed since 1994. They are managed concurrently under the umbrella of the Family Nutrition Education Programs (FNEP). Many other states' Extension programs operate these two programs concurrently, although this is not necessarily a requirement.

\section{Organizational Analysis}

FNEP as a program is complex and multi-faceted, but it pales in comparison to the University of Missouri System as a whole. Within the system of MU, there are four separate campuses and Extension. The four campuses of the system each have their own branch underneath the system umbrella. Extension, however, is not its individual branch; 
it reports to the Columbia campus ("History of the University of Missouri," 2016). Being associated with the flagship campus and having MU Extension's administration closely aligned with the campus in Columbia is valuable in a lot of ways. There is the recognizability of the University of Missouri, its name, and its logo, which Extension gets to utilize. There are also resources associated with the flagship campus, and the connection to the research faculty on campus. Conversely, Extension, however a part of the larger campus, is not a visible entity on campus like other university departments, which can create disconnects throughout the system.

The organizational issues also trickle down where Extension falls in the system's structure. Specifically, the multi-layered administrative structure of FNEP can be analyzed to better understand the organization. The administration is tasked with managing a multi-million-dollar program, employing over 100 people, and making decisions. Administrators have to make decisions based on scarce resources, thus creating a power dynamic within the rest of the organization (Pfeffer \& Salancik, 2005/1978). Organizational decisions are not made in a vacuum; there are external forces at play in the decisions, in addition to internal needs. Administrators and their decisions often have to meet the demands of their missions, their employees, and their funders. They are consistent with the description of Mintzberg's (2005/1979) strategic apex. The strategic apex is those who bear the overall responsibility for the organization, FNEP in this case. Those who provide resources to organizations are often in power behind-the-scenes. Program funders maintain power, which could be considered either reward of coercive (French \& Raven, 2005/1959). Despite viewing organizations as independent entities, they are resource-dependent and the University of Missouri Extension is no different. 
FNEP is entirely grant-funded and is accountable to funders, who exert their power by setting guidelines for program activities and uses of funds.

Past the state-level administration, a level of leadership exists at the eight geographic regions. There is an administrative unit in each region consisting of a project director and a program manager. These administrative units are consistent with Mintzberg's (2005/1979) Middle Line part of the organization. These positions have formal authority and are the middle-line managers between the Strategic Apex, the head of the organization, and the Operating Core, those who perform the daily duties and job functions. The Operating Core of FNEP is the nutrition program associates, those who daily fulfill the mission and priorities set forth by the grant. These differences between Middle Line management can be explained through both a leadership and organizational context. The organization's structure can be explained using Bolman and Deal's (2008) structural and human resource frames. The structural frame addresses the organization based on configuration alone. The organization's structure in of itself establishes consistency across the eight geographic regions as they all are made up a two-person administrative team, composed of a project director and a program manager. The structure is currently designed for consistency, which exists in structure, but does not extend to leadership. The human resource frame uses a lens of the people within the organization to provide understanding. The issues of differences in leadership style and management practices are more impacted by the individual people who inhabit those positions (Northouse, 2013). Without formal guidance, individual leadership approaches vary greatly. Some statewide guidance exists for managers, although only a few years 
ago, none existed. Continued efforts and mandates for more consistent leadership practices are needed (Bolman \& Deal).

The administration also limits the regional manager's control within the program. The upper levels of administration create a complex dynamic within the three layers of management: the upper level, the regional managers, and the paraprofessional educators. These align with the five basic parts of an organization, the Strategic Apex, the Middle Line, and the Operating Core, respectively (Mintzberg, 2005/1979). The highest levels of management, the Strategic Apex, make decisions based on political powers in play, and these factors are highly invisible to the other levels, specifically the paraprofessional educators. In viewing the organization as a political agent, the manager becomes a politician (Bolman \& Deal, 2008). These politicians, at the highest level, balance demands from funders, managers, and paraprofessional educators. The Strategic Apex, also utilizes their legitimate power as heads of the program, in order to exert influence (French \& Raven, 2005/1959). The Middle Line, the local area supervisors, balances the needs of their paraprofessional educators, who they interact with daily, and their administrators. Just like elected officials, conflicting demands occur for managers; they answer to their constituents who have individual-level problems, look at systemic issues, and balance the issues with scarce resources. The organization's structure in of itself establishes consistency across the eight geographic regions as they all are made up a twoperson administrative team, composed of a project director and aprogram manager. The structure is currently designed for consistency and structure. Those who occupy these positions are given formal authority consistent with their positions (Mintzberg). The final layer, the paraprofessional educators, or Operating Core, perform the basic and essential 
functions to the organization. Although they do not embody any formal power, they can use their collective role as the organization as a form of coercive power, as exampled by the classification of position titles (French \& Raven).

Within the Family Nutrition Education Programs (FNEP) an issue of two job titles for nutrition paraprofessional educators existed: nutrition program associates and nutrition program assistants. The working job descriptions of these two positions are the same, the main distinction between the positions was associates must have an associate's degree and assistants must have a high school diploma. Often, overqualified individuals filled assistant positions because there was only one paraprofessional educator position available. This was problematic because of the pay discrepancy between the positions. The associate positions starting pay is $\$ 11.80$ to $\$ 13.30$ an hour and the assistant positions starting pay is between $\$ 7.70$ and $\$ 9.10$ an hour. Because annual raises are $2 \%$, starting salary is important in determining long-term wages.

When looking more closely at the dilemma presented, the lack of clarity between these positions can inadvertently cause employees to feel devalued by the organization (Bolman \& Deal, 2008). According to Maslow's Hierarchy of Needs, when selfactualization and esteem needs are not met, employees are not benefitting from the organization. The organization no longer exists to meet the needs of the individuals (Maslow, 2005/1943). This issue was creating momentum under the surface. While the administration was looking into making changes, a group of assistants were joining together and speaking out regarding their positions, utilizing their coercive power (French \& Raven, 2005/1959). This highlighted the importance of the organization having a structure and system in place which can benefit the employees as well as the programs. In 
July of 2014, all nutrition program assistants were reclassified to nutrition program associates and given pay increases to the level of the associates. The assistant title is no longer used within FNEP and all new employees are hired as associates. This is an example of the organization being responsive to the needs of the program and of the organization. It was able to adapt its structure accordingly as needs changed.

\section{Leadership Analysis}

The Family Nutrition Education Programs' (FNEP) centralized administration is housed at the main campus of the University of Missouri. It consists of a program director, state coordinator, and approximately ten people who serve in various support or programmatic functions. The program director and state coordinator align with the Strategic Apex part of an organization (Mintzberg, 2005/1979) and the other ten campusbased staff as more of the support staff role (Mintzberg). Having a centralized leadership function serves many benefits, including having one centralized place for the overall program leadership and for program standardization. The standards include quarterly updates where the entire state team and all eight regions project directors and program managers come together. These meetings serve to provide standardization to the program and to the paraprofessional educators but do not include standardization expectations for administrative units.

To illuminate the lack of leadership direction and consistency in the program, the newly implemented unit reviews will be discussed. During these reviews, the state coordinator and a team visit two units a year and conduct surveys of all staff in the unit, observe the nutrition education in the community and evaluate administrative practices. These reviews were presented to leadership as a way to ensure consistency among the 
regions. A formal protocol was never created, nor is any direction or guidance provided to units before the review begins. Formal follow-up has taken many months for past reviews. The written report provided is sent via email without any additional conversations or follow-up as to changes to be addressed. The perceived intention of these reviews was for standardization when they created anxiety, uncertainty, and fear in leaders instead. Without a guiding philosophy and standardization of the review process, these reviews will likely cause more harm to the leaders than benefits to the overall program, especially if the findings are not utilized in a productive manner to benefit both the unit being reviewed and the entire program.

Two fundamentally different leadership practices can be understood through McGregor's Theory X and Theory Y. McGregor (1957) proposes two distinct management styles: Theory $\mathrm{X}$ and Theory $\mathrm{Y}$. Theory $\mathrm{X}$ is based on managers' beliefs employees work best by directing efforts and control employee actions. Inversely, Theory $\mathrm{Y}$ is based on the belief people achieve best by being motivated to direct their own efforts toward organizational goals. The two types of managers can complete some of the same management functions, but their attitudes and beliefs about their employees are far more telling and more predictive of behaviors toward individuals. Those who believe Theory $\mathrm{X}$ are more likely to micromanage, distrust employees' capabilities, and create an uncomfortable work atmosphere. The traits of Theory Y closely align with authentic leadership's components of self-awareness, internalized moral perspective, balanced processing, and relational transparency (Northouse, 2013). The ability of a leader to be reflective, to self-regulate, to analyze objectively, and to be open in sharing oneself with others are essential to connecting on an authentic level with employees. In order to 
objectively view others and treat them autonomously, a leader should possess these selfregulatory behaviors (Northouse). These two vastly different leadership styles are illuminating of the immensely different impacts leaders can have without consistent leadership expectations. The program would benefit from a guiding leadership philosophy, which could also help affect and influence decision-making, both at the state and the local level.

The current leadership practices of administrative units, or the Middle Line (Mintzberg, 2005/1979), have not been evaluated or standardized. The need for a leadership path is evidenced by the lack of clarity and purpose in the upper-level administration's actions. The unit reviews illuminate the lack of a guiding leadership philosophy by which to guide an evaluation of this nature. According to Roethlisberger (2005/1941), "a human problem to be brought to a human solution requires human data and human tools" (p.158). The issue of leadership discrepancy between people needs evaluation, guidance and the tools by which to enact change. The longevity of this program is evident and in order for continued success, leadership practices and strategy should plan for the future of the program, regardless of the individuals leading the program. The adoption of Sustainable Leadership (Hargreaves \& Fink, 2006) will guide leadership behaviors and create a pathway for consistency, longevity, and provide solutions within the program and work within the program.

\section{Implications for Research in the Practitioner Setting}

FNEP is a constantly moving target. The nature of the program dictates change occurs consistently and specifically to federal funders' guidelines. Yearly, federal guidance is released and SNAP-Ed providers must apply for their grants either annually 
or every three years ("The History of SNAP", 2015). Because of this fact, this poses the organization in a place for continual change and improvement to occur as needed. Since my tenure with Extension, the researcher has seen great change in regional realignment of the organization. As well as smaller changes within the program have occurred, including reclassifying paraprofessional educator positions to ensure consistency and fairness. This history and evidence of change illustrate how FNEP is able to adapt to shifting and changing environments. This research can assist to inform future change, and have implications for paraprofessional educators, leaders, and the entire program. Through first examining leadership practices, a baseline of what leadership practices are currently being utilized will be established, and then an analysis conducted to determine if they are consistent with the Sustainable Leadership theory (Hargreaves \& Fink, 2006).

Simultaneously, an effort to determine the level of engagement with employees, based on Kahn's (1990) theory will be conducted and later compared to the existence of sustainable leadership practices. Individually these two factors, leadership and engagement, have the potential to impact the individuals within the program as well as the program as a whole. Additionally, together they could demonstrate correlations between these facets or communicate no such relationship exists.

The federally funded programs are also moving away from a focus on direct education and are emphasizing the importance of impacting policies, systems, and environments (United States Department of Agriculture, 2016). With new emphasis, FNEP will need to make adjustments in where financial resources are distributed, resulting in less for paraprofessional educators and more for large-scale programs impacting these new ideas. As the program changes focus dramatically, evaluating what 
practices are effective at creating positive engagement will only become more important. As the number of paraprofessional educators' decreases, the program will likely need to be more administratively lean, and those administrators will serve an even more important function. Conducting research to begin to examine these leadership practices and then using these results to inform best practices and standards could provide the much-needed structure to a large and complex program.

\section{Summary}

For the second section, context and understanding related to the practitioner setting were presented. This began with a history of the University of Missouri, Extension, and the Family Nutrition Education Programs. Then, an analysis of the organization was presented, citing relevant scholarship, then leading into a more specific analysis of the leadership within the Family Nutrition Education Programs. These analyses are productive in understanding the structural and leadership issues of the proposed research study. Finally, implications for research in the practitioner setting was discussed. The leadership and organizational analysis help provide further contextual and theoretical understanding of the issues related to the research study and how the study can create impact on the practitioner setting. 


\section{SECTION THREE}

SCHOLARLY REVIEW FOR THE STUDY 


\section{Introduction}

Cooperative Extension organizations in all 50 states and United States territories implement nutrition education through two national programs, SNAP-Ed (Supplemental Nutrition Education Program Education) and EFNEP (Expanded Food and Nutrition Education Program). These programs provide education on nutrition and physical activity in schools, food pantries, homeless shelters, and other organizations serving low-income audiences. These programs nationally employ paraprofessional educators to provide the nutrition education ("The History of SNAP," 2015; United States Department of Agriculture, 2013).

In efforts to ensure consistency and quality, national and corresponding state standards exist for professional educators in the form of paraprofessional educator "Core Competencies." These competencies include standard expectations for teaching, reporting, and personal accountability ("Core Competencies- EFNEP \& SNAP-Ed," 2015). The importance of standardization, however, does not extend to the leaders of these paraprofessional educators. No standards exist for leaders of paraprofessionals in these organizations. This review of literature was an examination of an existing leadership theory, sustainable leadership, in order to establish a guiding set of principles in which to guide the research. Also, Kahn's (1990) theory of employee engagement was used as an additional conceptual framework to reveal the ways leaders can impact employees. Then, existing research on leadership and employee engagement and the employee impacts was reviewed and critiqued. Gaps in existing research were exposed in order to provide a framework for future research to occur. 


\section{Leadership as a Theoretical Framework}

Leadership is used as the theoretical framework used to provide insight and understanding to the issue of equitable leadership practices within University Extension programs. Northouse (2013) defined leadership as "a process whereby an individual influences a group of individuals to achieve a common goal” (p. 5). This definition utilizes the word process to imply the transactional nature of this relationship; leaders affect their followers and followers affect their leaders. The use of leadership for this study is to guide an examination of what practices are being utilized and how they either contribute positively or negatively to the organization as a whole. The theories of authentic (Walumbwa et al., 2008), team (Hill, 1982), and sustainable leadership (Hargreaves \& Fink, 2004) were analyzed within the context of nutrition programs to determine their usefulness in evaluating current practices and informing future guidance on expected practices.

The first of these proposed leadership theories, authentic leadership, focuses on the ability of a leader to be reflective, to self-regulate, to analyze objectively and to be open in sharing oneself with others. When these traits are possessed, leaders are able to connect on an authentic level with employees. "Walumbwa et al. (2008) conceptualized authentic leadership as a pattern of leader behavior that develops from and is grounded in the leader's positive psychological qualities and strong ethics" (Northouse, 2013, p. 254). To explain this theory, Walumbwa et al. introduced four components of authentic leadership: self-awareness, internalized moral perspective, balanced processing, and relational transparency. Self-awareness describes the process through which leaders develop personal insights into their strengths and weaknesses and how they can impact 
others. Being self-aware helps ground leaders' decisions and actions in what they believe to be right, as well as self-aware leaders are viewed as more authentic (Walumbwa et al.). The next component, internalized more perspective provides leaders to have control over how they let others influence them because they rely on their own beliefs and values rather than external pressures (Walumbwa et al.). "Others see leaders with an internalized moral perspective as authentic because their actions are consistent with their expressed beliefs and morals" (Northouse, p. 264). In addition, balanced processing is the act of soliciting input and opinions in decision-making and being able to analyze objectively. This trait is considered authentic because of their openness and willingness to be objective when considering others' opinions as well as their own (Walumbwa et al.). The last component of authentic leadership according to Walumbwa et al. is relational transparency. This describes controlling the level of self-shared with others. Authentic leaders are open in the presentation of themselves, which includes both positive and negative aspects. These four traits together create the basis of authentic leadership.

These traits are desirable to an Extension program where leaders work autonomously (Northouse, 2013). They alone are responsible for the well-being of their unit and their employees. This can be very rewarding and beneficial to employee and leader if the leader has these self-regulatory behaviors and abilities. If the leader lacks the ability to be self-aware and self-reflective, authentic leadership does not have the ability to be implemented. It relies more heavily on the individual leader's characteristics than the behaviors or priorities exhibited and would be difficult to regulate. Critics also point out limitations of authentic leadership. First, the moral component is not clearly explained and relies too much on individual interpretation while "it is not clear how 
authentic leadership results in positive organizational outcomes" (Northouse, p. 269).

For these reasons, authentic leadership was ruled out for use as a theoretical framework for this study. A later theory proved to be a better fit as an overall construct.

The next leadership theory examined as framework for the problem of practice is team leadership. The Hill (1982) model is "based on the functional leadership claim that the leader's job is to monitor the team and then take whatever action is necessary to ensure team effectiveness." (Northouse, 2013, p. 289). This model is multi-faceted. It begins with leadership decisions, then emphasizes leadership actions, both internal and external, and focuses on the overall team's effectiveness. The first portion of the model is the leader's decisions. This model provides a guide to assist leaders with problemsolving in choosing appropriate courses of action. Those leadership actions can be either internal or external. The internal actions often include tasks leaders should complete, as well as relational duties such as coaching and managing conflict. The external actions are mainly environmental, including networking and advocating. Leaders should be able to understand when it is appropriate to take internal or external actions and how those actions impact the team's effectiveness (Hill, 1982).

Although Extension nutrition programs work as a team, as all members' work toward the same goal, they all work independently of each other. The overall success of the program is dependent on everyone succeeding, but their day-to-day work is not dependent on one another. Additionally, critics of team leadership suggest despite its complexity, team leadership does not include all possible leadership skills. It also makes assumptions about the skills the leader already possesses such as "group process, decision making, interpersonal communication, conflict resolution, and other abilities" 
(Northouse, 2013, p. 306). These assumed skills are essential to the success of this leadership theory and if a leader does not possess these skills, there is no framework by which to provide guidance. The combination of these factors is why team leadership was ruled out as the conceptual framework for the proposed study. Although on the surface, team leadership appears to be appropriate, it does not accurately reflect the program from how it operates or how the paraprofessional educators interact and makes too many assumptions about the skills the leaders must already possess.

In addition, neither authentic or team leadership theories discussed issues of longevity or issues of diversity (Northouse, 2013). These are essential facets because the nutrition programs have been in operation in Missouri since 1969. In that time, many leaders have served in the varying geographic regions within Missouri. Oftentimes, paraprofessional educators and support staff outlast the leaders themselves in tenure; the longest-running employee served in one region for 42 years before retirement. The theory used to guide this program needs to provide the tools to create consistency within the different geographical regions as well as provide the structure to withstand leadership transitions. Furthermore, the Family Nutrition Education Programs seek to serve a lowincome audience and hire paraprofessional educators so they can reflect the target population. A commitment to diversity, both from a staffing perspective and from a programmatic perspective, are essential to maintain the integrity of the nutrition program. Sustainable Leadership theory provides the structure and tools needed to accomplish these tasks. 


\section{Sustainable Leadership as a Conceptual Framework}

The conceptual framework chosen to guide the proposed study is sustainable leadership. Hargreaves and Fink (2006) define sustainable leadership as:

sustainable educational leadership and improvement preserves and develops deep learning for all that spreads and lasts, in ways that do no harm to and indeed create positive benefit for others around us, now and in the future (p. 17). This definition illustrates how learning is essential to the principles of sustainable leadership and how the individual currently serving only serves a small portion of an organization's history. A definition used by Visser and Courtice (2011) stated, "a sustainability leader is someone who inspires and supports action towards a better world" (p.3). This simplified definition exemplifies the same principles as Hargreaves and Fink's definition. The context of this definition is the Cambridge Sustainability Model, which was created and tested with business leaders. Additionally, Avery and Bergsteiner (2011) utilized sustainable leadership within a business perspective, but access many of the same fundamental ideas, leaders must look at how decisions impact the entity in a long-term, rather than immediate manner. Much of the applied research on sustainable leadership is from a business perspective, while educational applications are mainly based on theory (Hargreaves \& Fink).

Hargreaves and Fink (2006) provided depth, length, breadth, justice, diversity, resourcefulness, and conservation as seven principles of sustainable leadership. The first three principles work together to create a three-dimensional understanding of sustainability, how depth, length, and breadth are interdependent. The following four complete the meaning and address additional challenges. 


\section{Depth}

The first sustainable leadership principle of depth is explained, "Sustainable Leadership matters. It preserves, protects, and promotes deep and broad learning for all in relationships of care for others" (Hargreaves \& Fink, 2006, p. 23). This principle focuses on two elements of leadership for learning: deep and broad learning and slow knowing. Deep and broad learning is a multi-faceted approach to learning, "is learning for meaning, learning for understanding, learning for life" (p. 33). Slow knowing focuses on how real and sustainable change and knowledge is not rapid. Taking the necessary time for change is essential for sustainability. This is the most essential of the seven principles. Sustainable Leadership focuses on learning first.

\section{Length}

The principle of length focuses on how the ability to successfully transition from one leader to another does not depend entirely on the succession plan, but it contributes. Effective coordination and planning of leadership succession create the capacity for continued improvement. Central to the outcome is the sharing of knowledge during the transition (Hargreaves \& Fink, 2006).

\section{Breadth}

Breadth builds upon the previous two principles. Success between leaders can also depend on the breadth of the knowledge spread. It can be essential during leadership transitions. Having distributed leadership can be both positive and negative to a learning environment. There are multiple patterns of distributing leadership, such as delegation, facilitated, and guided. These each have pros and cons, but in order to be successful, 
leadership distribution must be both deliberate and thoughtful (Hargreaves \& Fink, 2006).

\section{Justice}

The principle of justice "does no harm to and actively improves the surrounding environment by finding ways to share knowledge and resources with neighboring schools and the local community" (Hargreaves \& Fink, 2006, p. 142). The first three principles together can create great leaders, but these leaders also must be aware of the needs of all in order to ensure justice and fairness. This requires leadership to think beyond themselves and their immediate environment and have a vision align with the overall good. Hargreaves and Fink succinctly detailed, "Sustainable Leadership is socially just leadership, nothing simpler, nothing less" (p. 158).

\section{Diversity}

The ability for a leadership to be sustainable, it must also address diversity, the fifth principle. In order to accomplish this, these efforts must align with the overall mission as well as the policies and procedures. Diversity must be a priority of all and be reflected not only in the action of the leader but the actions of the entire educational organization (Hargreaves \& Fink, 2006).

\section{Resourcefulness}

Resourcefulness proves to be an essential piece as the sixth principle. Healthy organizations and leaders are aware of their existing resources and the finite nature of them. Often, resources are overused, thus, depleting what is available (Hargreaves \& Fink, 2006). This path, however, does not lend itself to sustainability. It is essential for a 
sustainable leader to be thoughtful about his or her use of resources and how it can impact the present, but also the future (Hargreaves \& Fink).

\section{Conservation}

Lastly, "Sustainable Leadership respects and builds on the past in its quest to create a better future" (Hargreaves \& Fink, 2006, p. 225). Most leadership theories ignore the importance of the past. Although it can be a source of resistance, it can also be a valuable resource of knowledge and history. The importance of the past to sustainable leadership is the ability to understand, appreciate, and then learn from what has already happened. It is important for organizations to understand what things are to be remembered and what should be forgotten. The ability to understand the difference and make the distinction embodies the principle of conservation.

The combinations of these seven principles create a cohesive and comprehensive theory of leadership to lend itself to understanding and promoting productive leadership within Extension nutrition programs. Boyatzis, Smith, and Blaize (2006) emphasized across all things they do and for their and their business' success, sustainable leaders must utilize compassion. Additionally, Galpin and Whittington (2012) underscored all their leadership approaches with the belief, an engaged workforce is the core of the sustainable leadership model. These principles can easily be aligned to existing leadership practices and help to provide guidance for leadership core competencies to result in sustainable leadership.

\section{Employee Engagement as a Theoretical Framework}

An additional theoretical framework, employee engagement, shifts the focus from the leaders to the employees. Kahn (1990) defined employee engagement as "the 
harnessing of organization members' selves to their work roles; in engagement, people employ and express themselves physically, cognitively, and emotionally during role performances" (p. 694). There are many employee engagement theories available, but three primary ones will be examined to determine which will be used as a conceptual framework: a job burnout perspective (Maslach, Schaufeli, \& Leiter. 2001), and the job demands-resources (JD-R) (Bakker \& Demerouti, 2007), and Kahn's theory of engagement (1990), model.

The first theory of employee engagement is based on research on job burnout (Maslach, Schaufeli, \& Leiter. 2001). Under this theory, engagement is operationally defined as the opposite of burnout and can be assessed by using the same inventories but opposite rating scales. According to Maslach, Schaufeli, and Leiter, job burnout occurs when there is incongruence between an individual and the following six areas: workload, control, rewards and recognition, community and social support, perceived fairness, and values. Conversely, the greater the match between an individual and these factors, the greater levels of engagement in the workplace. The researchers also suggested the mediating relationship between these factors and work attitudes. The job burnout perspective is not widely studied or considered to be a leading theory in employee engagement scholarship (Saks \& Gruman, 2014). It is oversimplifying the complexities of the conditions and factors which determine employees' ability to engage and subsequently, burnout from their work. According to Leon, Halbesleben, and PaustainUnderdahl (2015), "the co-existence of simultaneous levels of burnout and engagement within an individual is not a unique idea (p. 90), which contradicts the fundamental understanding of engagement in this theory. In order to understand the relationship 
between engagement and burnout, each requires more definition and measurement (Leon et al., 2015). Other critics argued “Kahn’s (1990) description of engagement may offer a better basis to reconceptualize engagement in a way that does not overlap with burnout (Schaufeli, 2013, p.11). For these reasons, the job burnout model was ruled out for consideration as the conceptual framework.

The most widely researched and evaluated theory is the job demands- resources (JD-R) model (Bakker \& Demerouti, 2007). Similar to the job burnout model, JD-R was developed from research on burnout, but this model expands to explain burnout through two factors: job demands and job resources. Job demands can include physical factors, such as work overload, time pressure, and role conflict. Conversely, job resources, come from the organization, such as compensation and job security. The theory's premise is a combination of high job demands and low job resources contribute to burnout or low job demands and high job resources lead to engagement. They are able to do this through activating internal motivations, help individuals cope with and buffer effects of job demands (Bakker \& Demerouti). JD-R “conceptualizes burnout and engagement as two separate constructs that are integrated in an overarching conceptual model" (Schaufeli, 2013, p. 16), which is a more complex understanding than the previous theory. Although, critics of the JD-R theory question if it truly a theory or "just a framework for classifying job demands and job resources" (Saks \& Gruman, 2014, p. 163). Although it is the most researched, the simplicity and the criticism it is a framework and not a complete theory are the reasons it was ruled out for consideration.

The last of these three potential conceptual frameworks is Kahn's (1990) theory of engagement. Kahn examined three psychological conditions to determine the degree 
of engagement at work. He determined the extent to which each of these was experienced determined the level of engagement. They are psychological meaningfulness, psychological safety, and psychological availability. Saks and Gruman (2014) explained, “employees who experience a greater amount of psychological meaningfulness, safety, and availability will engage themselves to a greater extent in their work role" (p. 160).

The overlap between these three employee engagement theories is great, and two focus specifically on engagement being a reverse of burnout. Maslach, Schaufeli, and Leiter's (2001) theory based on job burnout can be viewed as simplistic in terms of understanding employee engagement and ignores the potential of many other psychological factors to impact the variable. Although JD-R only provides two constructs, job demands and job resources, to explain the complicated nature of burnout and engagement (Bakker \& Demerouti, 2007). Although the most widely used engagement theory, JD-R “does not provide a theoretical basis as to why certain job resources will be related to engagement" (Saks \& Gruman, 2014, p. 171). Kahn's (1990) theory of employee engagement will be used as the second conceptual framework for this study because it is theoretically rich, and its three facets provide for greater understanding and analysis than the narrow frames of the other two theories presented.

\section{Kahn's Theory of Engagement as a Conceptual Framework}

Kahn's (1990) theory of engagement is the conceptual framework presented for this review of literature because as. Saks and Gruman (2014) argued, it was a more convincing theory than JB-R and job burnout because "it specifies the psychological conditions that lead to engagement as well as the factors that influence each of the 
psychological conditions" (p. 163). Similarly, the other two presented theories are oversimplified and more of a framework than a theory for classifying job demands and resources without a nod for the complexities of psychological factors (Saks \& Gruman). Kahn presented his theory by explaining:

People can use varying degrees of their selves, physically, cognitively, and emotionally, in the roles they perform, even as they maintain the integrity of the boundaries between who they are and the roles they occupy. Presumably, the more people draw on their selves to perform their roles within those boundaries, the more stirring are their performances and the more content they are with the fit of the costumes they don (p. 692).

Thorough understanding underlies Kahn's theory of how each aspect of an individual impacts multiple aspects of their lives and the more congruency, the greater degree they are going to assimilate or be engaged in all those facets. The three psychological conditions Kahn presents as pillars to his theory of engagement: psychological meaningfulness, psychological safety, and psychological availability. According to Kahn, "together, the three conditions shaped how people inhabited their roles" (p. 703).

\section{Psychological Meaningfulness}

Kahn (1990) explained psychological meaningfulness as the feeling of receiving a return on self-investment of one's roles. These feelings are associated when individuals

feel useful, valuable, and of individual worth. Furthermore, meaningfulness is associated with being appreciated and making a difference. Related to work tasks, "when organization members were doing work that was challenging, clearly delineated, varied, creative, and somewhat autonomous, they were more likely to experience psychological 
meaningfulness" (p. 704). In addition to tasks, roles at work can influence

meaningfulness in two significant ways. First, roles can carry identities that individuals must assume, such as the role of supervisor expected both to be mentor and monitor. Meaningfulness is associated when an individual identifies with one more closely, although identifying with neither can be negatively related to meaningfulness (Kahn, 1990). The second, the roles carry influence or a stature. Gaining a certain sense of status associated with a position can contribute to meaningfulness. Lastly, the interactions workers experience can also influence meaningfulness, as interpersonal relationships can be psychologically beneficial (Kahn).

\section{Psychological Safety}

Psychological safety is the ability for employees to feel safe and secure in their work by being able to be themselves without fear of negative consequences. This sense of safety is associated with trust in the ability to engage (Kahn, 1990). The ability for individuals to feel psychologically safe relies on interpersonal relationships, group dynamics, management style, and organizational norms. Interpersonal relationships and group dynamics both required positive and trusting relationships to exist, both on an individual and group level. When those exist, individual are able to attempt new things without fear of failure and retribution. Much like the positive impact of interpersonal relationships, supportive management practices also contribute to safety. Conversely, "fear was compounded when managers were unpredictable, inconsistent, or hypocritical" (p. 711). Lastly, when people are able to work within the norms of the organization, safety can be improved. Individual work expectations need be aligned with the overall 
set of standards and individuals feel they can work freely within those protective boundaries.

\section{Psychological Availability}

The final construct of psychological availability is the capacity to be able to personally engage in a given moment. "It measures how ready people are to engage, given the distractions they experience as members of social systems" (Kahn, 1990, p. 714). Four facets can impact availability: physical energy, emotional energy, insecurity, and outside life. Under Kahn's definition of engagement, a certain level of physical energy is required for active engagement that is not required for disengagement. Much like physical energy, a great deal of emotional energy is required in order to be engaged, while the absence of it is consistent with being disengaged. Further, the relationship between security and psychological availability is important; individuals who are insecure are not able to bring their full selves to work, contributing to their inability to engage productively (Kahn). The role of outside lives on engagement is generally considered to be a negative interaction; outside lives draw us away from our formal work roles and contribute to disengagement. The opposite also has the potential to be true, people are able to increase availability and draw on energy created from outside of work to increase their psychological availability (Kahn). By utilizing employee engagement as a second conceptual framework, engagement allows for constructs to focus on the paraprofessional educators within Extension nutrition programs and give structure to tell the story of how leadership practices impact them. 


\section{Available Literature}

The available literature on leadership, paraprofessional nutrition programs and employee engagement was presented to provide an understanding of what inquiry has already been studied. The existing research was critiqued and synthesized, guiding further understanding of the inquiry.

\section{Leadership and Paraprofessionals}

Although Extension nutrition programs have been around for almost 50 years, limited research has focused on paraprofessional outcomes, and even fewer looked specifically at the relationship between leadership and paraprofessional outcomes (Dickin, Dollahite, \& Habicht, 2009). Studies make connections between leadership and these outcomes will be described, not focusing specifically on sustainable leadership because the connection between those two constructs has not been made. Research on sustainable leadership is very limited, primarily focusing on theory (Hargreaves \& Fink, 2007; Hargreaves \& Fink, 2006; Hargreaves \& Fink, 2004) and leadership sustainability within business (Avery \& Bergsteiner, 2011; Boyatzis, Smith, \& Blaize, 2006; Galpin \& Whittington, 2012). Avery and Bergsteiner described how using sustainable leadership is a long-term perspective and approach for business decision-making. This contradicts the long-held shareholder-first philosophy. These researchers argued how making long-term decisions utilizing a sustainable approach positions not only the shareholders but the employees and the company as a whole in a better position for the future. They stated, "the objective of sustainable leadership is to keep people, profits, and the planet in balance over the life of the firm and in so doing ensure that the business generates the social capital needed to weather downturns (Avery \& Bergsteiner, p. 6). Visser and 
Courtice's (2011) model viewed internal and external leadership context as impacting the individual leader, who in turn, has two-way relationships with their leadership actions (internally and externally). Internal leadership is viewed as the things within the organization of which leaders generally maintain control, while external leadership contexts are the things that often happen to the organization that are outside of the control of the leader (Visser \& Courtice).

Additionally, one study focused specifically on promoting positive sustainable leadership in leaders themselves. Boyatzis, Smith, and Blaize (2006) explained: Leaders are more likely to be effective and resist the effects of chronic, power stress if they are physiologically and psychologically balanced. We further suggest that leaders who coach others with compassion will stimulate internal processes that enable them to balance the toxic effects of power stress inherent in their roles as leaders and in performing the role effectively. Thus, coaching with compassion may provide the platform for Sustainable leadership effectiveness and an effective approach for developing leaders- to teach them how to effective engage and develop other leaders (p. 8).

Specifically, this research could have important implications as the connection between sustainable leadership and engagement of paraprofessional educators is made. Galpin and Whittington (2012) explained, "At the core of the sustainability leadership model is an engaged workforce. Workforce engagement is a central element of transforming a firm's sustainability mission" (p. 41). This connection between sustainable leadership and engaged employees is important as this research seeks to find a similar connection in community nutrition programs. 
Research on leadership in nutrition education programs included an examination of job satisfaction and retention of paraprofessional educators utilizing quantitative data (Dickin, Dollahite, \& Habicht, 2010). A survey of nutrition paraprofessional educator's job satisfaction and intention to leave found paraprofessional educators who believe in the program's effectiveness are more satisfied and less likely to plan to leave (Dickin, Dollahite, \& Habicht, 2009). Having a voice in decision-making was the management practice related strongest to job satisfaction (Dickin, Dollahite, \& Habicht, 2009). Moreover, Dickin, Dollahite, and Habicht (2011) conducting a mixed-method study, found high levels of perceived program value, supportive supervision, and autonomy were all positively related to job satisfaction. Nevertheless, pay was not the primary motivation for paraprofessional educators. Dickin, Dollahite, and Habicht (2011) argued, “community nutrition educators' appreciation of their freedom and the guidance from supervisors conveyed the importance of supervisory styles that balance the granting of autonomy with monitoring and advice" (p. 266). Furthermore, Okello and Gilson (2015) conducted a systematic review to explore the influence of trust relationships on motivation in the health sector. The researchers found trusting work relationships encouraged social interaction and cooperation and were related to workers' motivations. Additionally, they found consequences for retention and performance of workers.

The existing research on leadership and paraprofessional nutrition educators established a positive relationship between leadership practices and employee outcomes, such as retention and job satisfaction (Dickin, Dollahite, \& Habicht, 2010). What does not exist yet is the relationship between sustainable leadership because it has not been widely studied. 


\section{Employee Engagement}

The second conceptual framework presented has been studied widely since it appeared in 1990, but has not been used specifically within the field of Extension nutrition programs. Utilizing a field study, May, Gilson, and Harter (2004) built upon Kahn's (1990) theory of engagement explored the relationships of the Kahn's theory's three principles: psychological meaningfulness, safety, and availability. All three constructs had significant positive relationships with engagement. The strongest of these three was meaningfulness. Additionally, the construct of psychological meaningfulness was positively related to job enrichment and work-role fit (May et al.). Harter, Schmidt, and Hayes (2002) conducted a meta-analysis of over 7,000 business units in 36 companies to examine relationships between employee satisfaction, employee engagement, and business outcomes. Significant relationships were found between employee satisfaction, employee engagement, and business outcomes. The strongest relationships were found with the business outcomes of employee turnover, customer satisfaction-loyalty, and safety. Positive relationships also existed for productivity and profitability, but not as strong as the previous variables.

Psychological safety was positively associated with rewarding co-worker and supportive supervisor relations, while a negative relationship existed with adherence to co-worker norms and self-consciousness (May et al., 2004). Additionally, Van den Broeck, Vansteenkiste, De Witte, and Lens (2008) examined Belgian employees on job characteristics, burnout and engagement and found:

Employees who are surrounded by resourceful job characteristics are more likely to experience a general feeling of psychological freedom (i.e., autonomy), 
interpersonal connectedness (i.e., belongingness), and effectiveness (i.e., competence), which in turn explains why they feel less exhausted, and more vigorous in their jobs. Employees who encounter many job demands, in contrast, seem to be more likely to have their basic psychological needs thwarted and therefore experience more exhaustion. (p. 288).

A positive relationship exists between psychological availability and available resources while having a negative relationship to participation in outside activities (May et al.). Furthermore, Crawford, LePine, and Rich (2010) found a positive relationship between demands and burnout and a negative relationship with resources and burnout. Between resources and engagement were consistently positive relationships, while the relationship between demands and engagement was dependent on the perception of the demand itself. "Demands that employees tend to appraise as hindrances were negatively associated with engagement, and demands that employees tend to appraise as challenges were positively associated with engagement" (p. 834). The research on Employee engagement illustrates the importance of external factors on the level of engagement.

\section{Summary}

Most of the research on leadership in community nutrition programs lends itself to program effectiveness and not employee outcomes (Dickin, Dollahite, \& Habicht, 2010). The existing studies examining this relationship were presented in this scholarly review. The available research, however, has not utilized Sustainable leadership as a conceptual framework by which to look at these outcomes. Most sustainable leadership research either focuses on theory (Hargreaves \& Fink, 2007; Hargreaves \& Fink, 2006; Hargreaves \& Fink, 2004) or is utilized in a business setting (Avery \& Bergsteiner, 2011; 
Boyatzis, Smith, \& Blaize, 2006; Galpin \& Whittington, 2012). Utilizing Sustainable leadership in relation to paraprofessional nutrition paraprofessional educators is a new approach. Additionally, existing research on Employee engagement established it as a strong construct by which to evaluate employee outcomes because of the rich relationship between engaged employees and positive employee outcomes. This review of the scholarly literature shows the vast gap in literature as Extension nutrition programs access Sustainable leadership as a guiding principle. Further, no studies have made connections specifically between Sustainable leadership practices and Employee engagement. The path for conducting the proposed study is clear to examine if these two proposed constructs have a relationship, the strength of the relationship, and the realworld implications for Extension nutrition programs if the relationship exists. 
SECTION FOUR

CONTRIBUTION TO PRACTICE 


\section{Introduction}

University Extension nutrition programs are far-reaching programs, with federal guidance dictating program direction and acceptable activities ("The History of SNAP," 2015; United States Department of Agriculture, 2013). These national standards provide some opportunity for flexibility for individual programs, but program priorities and focus areas follow the expected practice guidelines. National programs thrive from standardization; this helps fundees communicate program value with funders to ensure their dollars are being used appropriately. These standards continue down to paraprofessional educators in the form of educator "Core Competencies" ("Core Competencies- EFNEP \& SNAP-Ed,” 2015). These competencies include expectations for teaching, reporting, and personal accountability. Furthermore, these programs import the value of standardization among programs both between and within states ("Core Competencies- EFNEP \& SNAP-Ed,” 2015). The existence of competencies ensures these programs, including the paraprofessional educators, are standard in program and values. Utilizing the same rationale and philosophy as used during the creation of paraprofessional educator core competencies, the existence of standards or core competencies for program leadership would also create standardization and clarity of roles among programs. In the case of Missouri, the local program coordinators serve as direct supervisors to the paraprofessional educators.

The purpose of this research study was to determine which sustainable leadership practices program coordinators within SNAP-Ed and EFNEP nutrition programs were using to manage and lead paraprofessional educators and to determine the level of engagement nutrition paraprofessional educators are experiencing within the workforce. 
Employee engagement is being utilized as the variable to evaluate the impact these practices have on paraprofessional educators (Kahn, 1990). Employee engagement was chosen because it is highly researched and has connections to many employee outcomes including job enrichment, work-role fit, and productivity (Harter, Schmidt, \& Hayes, 2002; May, Gibson, \& Harter, 2004). Additionally, this study seeks to understand if a connection exists between the use of sustainable leadership practices and employee engagement. Galpin and Whittington (2012) explained, "at the core of the sustainability leadership model is an engaged workforce. Workforce engagement is a central element of transforming a firm's sustainability mission” (p. 41). This connection between sustainable leadership and engaged employees is important as this research seeks to find a similar connection in community nutrition programs.

Similarly, this study sought to fill a gap in the existing research on Extension nutrition programs. Literature of these programs covers many areas: the paraprofessional educators, program effectiveness, and even the type of information collected from the participants (Dickin, Dollahite, \& Habict, 2010; Dickin, Dollahite, \& Habict, 2011; Okello \& Gibson, 2015). A gap exists in the literature, however, in a significant study of the leaders, what practices they use, and how they impact the paraprofessional educators and the program. The available literature establishes a relationship between managerial practices and employee outcomes (Dickin, Dollahite, \& Habicht, 2009), but not enough to understand specifically what practices are used and how to replicate them.

The University of Missouri Extension's Family Nutrition Education Programs were used as the setting of this study. Similar programs exist nationwide, the University of Missouri was used because the researcher had access to conduct the study at this 
location. The program is divided into eight geographic regions and they were each studied so the data could be examined as a whole and separated by geographic region. These results could be utilized nationally and by other Extension nutrition programs. The federal funding level for 2016 was $\$ 408$ Million dollars for all of the SNAP-Ed programs nationally. This funding is historically controversial because of its large number as well as because it is a part of the larger SNAP budget ("The History of SNAP," 2015; United States Department of Agriculture, 2013). The research proposed should guide policy and programmatic changes to potentially increase the retention and satisfaction of the workforce, continuing to benefit the program as a whole. In order to guide this study, the researcher proposed a host of questions to inform the study's constructs: sustainable leadership and employee engagement.

\section{Research Questions}

The research questions guiding this study are:

1. Do the leadership practices of program administrators within the University of Missouri Extension align with Sustainable Leadership principles?

2. Is there a difference between the program administrators within the University of Missouri Extension's reported sustainable leadership practices and the paraprofessional educators' perceptions of their administrators' sustainable leadership practices?

3. What is the reported level of employee engagement of nutrition paraprofessional educators within the University of Missouri Extension nutrition programs? 
4. Is there a relationship between the level of sustainable leadership practices used by program administrators and employee engagement scores of nutrition paraprofessional educators?

\section{Conceptual/Theoretical Framework}

In order to fully realize and provide the framework necessary to understand this study and its meaningfulness, two separate frameworks are presented: sustainable leadership (Hargreaves \& Fink, 2006) and employee engagement (Kahn, 1990).

\section{Sustainable Leadership}

The theoretical framework of leadership provided a guide for understanding how leaders' practices can impact those they manage, as well as the programs they coordinate. For the purpose of this study, sustainable leadership was used to provide understanding and analysis of the leaders' behaviors because it identified seven distinct principles; these principles can be easily understood, researched, and applied to the nutrition program leaders. It was also the only theory to emphasize diversity or longevity (Northouse, 2013).

Hargreaves and Fink (2006) introduced seven principles of sustainable leadership. The seven principles of sustainable leadership are depth, length, breadth, justice, diversity, resourcefulness, and conservation (Hargreaves \& Fink). These seven principles interacting together is what provides uniqueness to this theory. At the core of an engaged workforce is the sustainable leader (Galpin \& Whittington, 2012).

The first sustainable leadership principle is depth. This principle focuses on two elements of leadership for learning: deep and broad learning and slow knowing. Deep and broad learning is a multi-faceted approach to learning, "is learning for meaning, 
learning for understanding, learning for life" (Hargreaves \& Fink, 2006, p. 33). Length, the second principle, is the ability to successfully transition from one leader to another while not depending entirely on the succession plan. Breadth builds upon the previous two principles. Success between leaders can also depend on the breadth of the knowledge spread. It can be essential during leadership transitions.

The first three principles together can create great leaders, but these leaders should also be aware of the needs of all in order to ensure justice and fairness. This requires leadership to extend beyond the immediate environment and have a vision aligned with the overall good, which is the fourth principle of justice (Hargreaves \& Fink, 2006). It is important in context of this theory because if leadership is to be long-lasting it also should have a moral compass, acting in the best interests of everyone. Further, is a focus on diversity. The ability for leadership to be sustainable, it should also embrace diversity. Diversity provides people the ability to adapt and learn in complex environments and learn from each other. These efforts must align with the overall mission as well as the policies and procedures (Hargreaves \& Fink). Contributing to the theory is the concept of resourcefulness. Healthy organizations and leaders are aware of their existing resources and the finite nature of them. The final of the seven principles is conservation which supports a leader who is able to value the past while looking to the future. Many leadership theories ignore the importance of the past. Although it can be a source of resistance, it can also be a valuable resource of knowledge and history (Hargreaves \& Fink). The combination of these seven principles creates a complex and thorough understanding of sustainability and can be simply defined as "a sustainability leader is someone who inspires and supports action towards a better world" (Visser \& 
Courtice, 2011, p.3). The combination of these seven principles create environments to make decisions for organizations and programs based on the greater good while accounting for the past, being resourceful and, looking to the future.

\section{Employee Engagement}

The use of employee engagement as an additional conceptual framework helps ground the use of the leadership practices in an understanding of outcomes for nutrition paraprofessional educators. Kahn's theory was chosen for the purpose of this study because it the most theoretically rich, examining the psychological aspects of employee engagement while the other two theories both operationalize engagement as the opposite of burnout.

In Kahn's (1990) theory of engagement, two constructs were presented: personal engagement and personal disengagement. Kahn defined personal engagement "as the harnessing of organization members' selves to their work roles; in engagement, people employ and express themselves physically, cognitively, and emotionally during role performances" (p. 694). Contrarily, Kahn defined personal disengagement "as the uncoupling of selves from work roles; in disengagement, people withdraw and defend themselves physically, cognitively, or emotionally during role performances" (p. 694). Kahn's theory of employee engagement examined personal engagement and personal disengagement through the lens of three psychological facets: psychological meaningfulness, psychological availability, and psychological safety. Other researchers believe Kahn's theory is a good way to conceptualize engagement without overlapping with burnout like many other employee engagement theories (Schaufeli, 2013) and the three psychological facets contribute to the rich theoretical understanding. 
Kahn (1990) explained psychological meaningfulness as the feeling of receiving a return on self-investment of one's roles. These feelings are associated when individuals feel useful, valuable, and of individual worth. Furthermore, meaningfulness is associated with being appreciated and making a difference. Psychological safety is the ability for employees to feel safe and secure in their work by being able to be themselves without fear of negative consequences. This sense of safety is associated with trust in the ability to engage (Kahn). The ability for individuals to feel psychologically safe relies on interpersonal relationships, group dynamics, management style, and organizational norms. Interpersonal relationships and group dynamics both required positive and trusting relationships to exist, both on an individual and group level. When those exist, individuals are able to attempt new things without fear of failure and retribution. Much like the positive impact of interpersonal relationships, supportive management practices also contribute to safety. The final construct of psychological availability is the capacity to be able to personally engage in a given moment. "It measures how ready people are to engage, given the distractions they experience as members of social systems" (p. 714). Four facets can impact availability: physical energy, emotional energy, insecurity, and outside life. "Personal engagement demanded levels of physical energy, strength, and readiness that personal disengagement did not” (Kahn, p. 714). Emotional energy similarly is required for availability. Being engaged requires a level of emotional investment in order to meet the demands of engagement. Insecurity is also essential, "for individuals to express their selves in social systems, they must feel relatively secure" (Kahn, p. 715). The fourth facet of outside life is impacted because of its ability to create a psychological separation from their roles and their ability to engage (Kahn). Saks and 
Gruman (2014) explained, "Employees who experience a greater amount of

psychological meaningfulness, safety, and availability will engage themselves to a greater extent in their work role" (p. 160).

\section{Methods}

Mixed methods was chosen to provide a better understanding of a problem than can be provided with only using either quantitative or qualitative approaches alone. More specifically, a procedure known as transformative mixed methods was used for this study. Transformative mixed methods incorporate both qualitative and quantitative research through a theoretical lens (Cresswell, 2013). The quantitative and qualitative data collection occurred concurrently, which is consistent with the principles of this approach. Additionally, using mixed methods better helped the researcher triangulate the data and to balance the strengths of the quantitative and qualitative approaches against each other (Cresswell).

\section{Study Setting}

The setting used to answer the research questions was the eight geographic regions of the University of Missouri Extension's Family Nutrition Education Programs (FNEP). Each of the eight geographic regions has a two-person administrative unit, including a project director and program manager. The project director is the direct supervisor of the paraprofessional educators and serves in an administrative capacity. They are responsible for performance, personnel, budgets, and all administrative decision. The program manager serves in a program support function while having some leadership responsibilities. They are responsible for training, curriculum, and overall program support to FNEP. 


\section{Study Participants}

In order to answer the research questions, two types of participants were recruited. The first were those in the leadership position; both project directors and program managers were identified and asked to participate in a qualitative interview. These were conducted either in-person or via videoconference. All but one leader agreed to participate, the sample size is seven project directors $(n=7)$ and five program managers $(n=5)$.

The second set of participants was current paraprofessional educators. An email listserv exists of all current paraprofessional educators employed at the University of Missouri Extension FNEP. This included 100 employees. The survey received 64 responses, a response rate of $63.4 \%$. This purposeful sampling was done for two reasons. The first was convenience; the researcher had easy access to conduct an online survey on all of these participants. Secondly, because of the structure of the organization, they all share the same job title and can easily be used to compare against their respective supervisors, who also all have the same job title (Creswell, 2013; Merriam, 2009). This is a natural place for comparison, as the organizational structure provides an established comparison point.

\section{Data Collection}

A mixed-method design was used in order to capture in-depth data from the leaders and to triangulate the data to the paraprofessional educators they manage (Creswell, 2013). Two distinct strategies for data collection were used. To collect data on what leadership practices are being used and if they relate to sustainable leadership principles, a qualitative interview was conducted with each leader. These semi-structured 
interviews lasted between 30-60 minutes and were conducted either in-person or via videoconference. All participants signed an informed consent (Appendix A) after approval of the University of Missouri IRB was given (Appendix C). The questions asked were open-ended, asking each leader to reflect specifically on their general leadership philosophies and specific examples of their use of leadership practices (Appendix B).

The second data collection was the use of an electronic survey sent to the current listserv of nutrition paraprofessional educators. Survey responses were anonymous; no identifying information was collected. The survey opened with an informed consent statement (Appendix A). It only asked the participants to identify in which of the eight geographic regions they work. The survey consisted of two parts. The first was an employee engagement inventory. The employee engagement inventory was the Utrecht Work Engagement Scale (UWES), which consists of 17 items to measure employee engagement (Appendix B). This is the most widely used employee engagement survey; it has been tested for reliability and validity in its many uses in research studies (Schaufeli \& Bakker, 2003; Schaufeli, Bakker, \& Salanova, 2006). Additionally, the survey sent to paraprofessional educators included a series of questions determining their perception of their program administrators' use of the seven sustainable leadership practices (Appendix B). This second portion of the survey was created by the researcher to add an additional point of analysis in order to determine if leaders' reported practices are consistent with the paraprofessional educators' perceptions of these same practices. It consisted of seven questions on a Likert-type scale asking the paraprofessional educators' perceptions of the sustainable leadership practices utilized by their region's administrators. Each question 
had a short-answer follow-up allowing the paraprofessional educator to give an example of a time this behavior was either utilized or not.

\section{Data Analysis}

The data analysis procedure was multi-step and addressed the four research questions.

Initially, the qualitative interviews were transcribed for ease of data analysis. The researcher then focused on coding by using Hargreaves and Fink's (2006) seven principles of sustainable leadership. Focused coding consists of line-by-line coding to identify themes (Emerson, Fretz, \& Shaw, 2011). The conceptual framework of sustainable leadership was used as the coding themes because it has already been established. Once the coding was complete, in order to conduct the later analyses, a numerical value was assigned to each of the eight administrative regions as well as an overall score for the entire program. Each administrative unit received a numerical score from 0 to 7 . For each of the seven sustainable leadership practices, one will be awarded for each of the seven practices the unit uses (could be either the project director or the program manager). For example, a unit identified both breadth and width as practices, received a score of 2 . Averaged scores ranged from 2 to 5 practices used per region. These seven scores were averaged to determine the average level of sustainable leadership practices across the entire program, average =3.6). Additionally, the paraprofessional educator responses to the 9-item questionnaire about their leaders' sustainable leadership practices was also used to provide information related to the research question. This first portion of the data analysis addressed the first research 
question, "Do the leadership practices of program administrators within the University of Missouri Extension align with Sustainable Leadership principles?"

The second research question, "Is there a difference between the program administrators within the University of Missouri Extension's reported sustainable leadership practices and the paraprofessional educators' perceptions of their administrators' sustainable leadership practices?" was answered by comparing two pieces of data using a t-test. A t-test was used because it is the preferred analysis for determining a correlation between two independent variables (McDavid, Huse, \& Hawthorn, 2013). The two numbers being compared are the numerical values assigned to the leaders' sustainable leadership practices and the average scores of the paraprofessional educator survey asking their perceptions of their leaders' sustainable leadership practices. In order to determine significance, alpha $<0.5$ which is considered a standard for stringent data analysis (McDavid, Huse, \& Hawthorn).

Then, the data collected from the paraprofessional educators was scored based on the Engagement Scale to determine employee engagement scores of each individual. Scores were calculated by adding all responses (1 to 6 ) and then dividing by the number of items (17) (Schaufeli, et al., 2006). Scores were averaged across all respondents and also amongst respondents from different geographic regions in order to provide a comparison point. Norm scores will be used to determine levels of employee engagement $($ Mean $=3.74, \mathrm{SD}=1.17)$. Very low $(<1.78)$, Low (1.78-2.88), Average (2.89-4.66), High (4.67-5.50), Very High (>5.50) (Schaufeli, et. al). This answered the third research question, "What is the level of employee engagement of nutrition paraprofessional educators within the University of Missouri Extension nutrition programs?" 
The average engagement score from each region underwent a t-test to determine correlation (alpha <.05) against the sustainable leadership score of each region to answer the final research question, "Is there a relationship between the use of Sustainable Leadership practices by program administrators and Employee engagement scores of nutrition paraprofessional educators?" A t-test was utilized because it is the preferred analysis for determining a correlation between two independent variables (McDavid, Huse, \& Hawthorn, 2013). Significance level was set at alpha <.05.

\section{Results and Discussion}

Presented in this section are the results of the study, of the qualitative and quantitative analysis. The discussion of the findings will draw connections from the study results back to the theoretical and conceptual frameworks presented.

\section{Research Question One}

The first research question sought to answer the question, Do the leadership practices of program administrators within the University of Missouri Extension align with Sustainable Leadership principles? The researcher answered this question in two ways; first, by conducting interviews of leaders and collecting self-reported leadership practices, the second, by having educators complete a survey of their leader's leadership practices. All leaders identified between two and five of the sustainable leadership traits during their interviews. They were asked open-ended questions about their leadership philosophy and practices as not to create bias in answering by directly asking about the seven traits. Overall, six of the seven traits were utilized by at least one leader, conservation not being identified by any. Table one provides a ranking of the most utilized traits, as well as examples of each from the leaders' interviews. 
Table 1 Ranking of Sustainable Leadership Traits

\begin{tabular}{lcl} 
Trait & Ranking & Example \\
\hline $\begin{array}{l}\text { Depth } \\
\text { box." }\end{array}$ & 1 & "I hope that I've gotten people to think outside the \\
$\begin{array}{l}\text { Breadth } \\
\text { program." }\end{array}$ & 1 & "Having a bigger picture view on the whole \\
Length & 3 & "Keep a similar model no matter what the change." \\
Justice & 3 & "Fair and consistent expectations for everybody." \\
Resourcefulness & 5 & "You can still make things work." \\
Diversity & 6 & "We have to be understanding of their needs." \\
Conservation & 7 &
\end{tabular}

Note: $\mathrm{n}=13$

The educators' perception of the use of sustainable leadership practices was collected via electronic survey. Short answer responses were gathered, as well as the average score for each trait on a 1 to 5 Likert-type scale from Strongly Disagree to Strongly Agree. The overall average across all seven sustainable leadership practices is 3.79. Overall, the responses indicate the paraprofessional educators somewhat agree with the use of sustainable leadership practices by their leaders. Table 2 illustrates the average scores and rankings across all seven leadership practices. 
Table 2 Ranking of Sustainable Leadership Traits (from Employee Survey)

\begin{tabular}{lcl} 
Trait & Ranking & Average Score (1 to 5) \\
\hline Resourcefulness & 1 & 4.26 \\
Diversity & 2 & 4.03 \\
Length & 3 & 3.98 \\
Justice & 4 & 3.84 \\
Breadth & 5 & 3.61 \\
Depth & 6 & 3.40 \\
Conservation & 7 & 3.37 \\
\hline
\end{tabular}

Note: $\mathrm{n}=63$

Depth. Five leaders verbalized the trait of depth during their interviews. One explained, "I hope that I've gotten people to think outside the box, also pushed people to places they weren't comfortable going. . . I don't think people necessarily like me for it, I hope that people have grown from it, the unit has grown from it." Additionally, another leader stated, "We need to be practicing what we are preaching. If we don't do what we are expecting other people to do, then they are not going to see us as viable resources."

The educators' survey responses rated the trait of depth at 3.40 on a Likert-type scale of 1 to 5. Examples of this trait provided include, "Our director has always provided training when new changes are put in place to make sure that the new information is fully understood," and "The director took time to explain why these changes were essential and worked with us to make sure we understood and answered any questions we had. She continually follows up and keeps us all on the same page." Additionally, one educator described their leader not utilizing the trait of depth as "It seems that our leaders 
talk about implementing a change but they never follow through with that implementation."

Length. The trait of length was articulated by three of the twelve leaders interviewed. One leader described how they implement this trait as:

I like to give my staff a head's up and kind of prepare them for change as I can. Whether that's this past week in a staff training and discussing these are things you might see coming in the next couple of weeks or if it's an email, you know briefly mention something they can expect so these things don't feel like big shocks, but feel like something they are more prepared for.

Additionally, another leader discussed how they implement their leadership consistently over time. "I came to that philosophy by just, every year has been different year to year, trying to keep a similar model no matter what the change or whatever it is."

The trait of length scored at 3.61 from the educator survey. One educator articulated how they felt their leader had implemented leadership that would be consistent in a transition. "I believe that my leader has things in good running order and that anyone following would transition well." Conversely, another educator aired grievances related to how the system operates. "I think that the Extension system runs extremely slow. The downtime between decisions (whether hiring related or otherwise) seems to be when negative consequences occur ... and the system continues to move extremely slow in resolving the issues that were created."

Breadth. Breadth was identified by five leaders as a trait they use to describe their leadership style. One leaders explained their leadership as "A lot of open communication, a balance of discipline, flexibility, and just having a bigger picture view 
on the whole program. What we are doing here, what we are doing at the state." Also, another leader placed emphasis broadly on the mission of the organization, "I feel like you have to understand our mission, you have to really understand what we're trying to do."

The trait of breadth was rated as a 3.98 out of 5 by the educator survey. The short answer section included the following description of this trait. "When conflicts have arose, our leaders listen to all sides of the store and look for the best solution for all.” Also, one educator described an action their leader takes while implementing change, "When change takes place, our leaders explain the changes and why they are essential. So, thoughtful and deliberate could be good describing words." Not all educator responses were positive. Once described rash action as "Reacts to what may be happening from campus. Starts implementing policy before a final decision has been made. In a lot of cases we have to take a step backwards because she changed things before a final decision was made."

Justice. Three different leaders expressed the understanding of justice as important in their leadership practices. One leader verbalized what they believed to be essential to leadership as having "Courage to make decisions ... having integrity, honesty ... being somebody that others can rely on and know that you will be truthful with them and that you will do what you say you will do." Another leader gave the example of "always having fair and consistent expectations for everybody."

The sustainable leadership trait of justice had an average score of 3.84 on the educators' survey. They described their leaders' use of justice was "They always want to follow FNEP procedures. They want everyone to do their best just as they do 
themselves" and "I think we are all human and that our leaders are intentional and thoughtful most of the time with decision making." Although not all the comments viewed their leaders positively related to justice. "They always mention that a situation/decision is fair to the group as a whole... not sure that it always falls where everyone is treated equally however."

Diversity. Diversity was only identified by one leader in their description of their prescribed leadership philosophy. They explained, "I think we work with a diverse group of women so we have to be understanding of their needs and their preferences, their learning styles and their working styles."

Although diversity was only articulated by one leader, it scored highly on the educators' surveys, a 4.03 on a 1 to 5 scale. One educator described actions taken by their leader as, "They encourage those members of our office from a different culture to share with the office during meetings, etc." Another educator acknowledged the diversity of their unit and the acceptance from their leaders, "We have a rather diverse group. They are willing to accept us all with our strengths and weaknesses." While, one educator said this about diversity in their geographic unit, "I just don't think it comes up very often in our area."

Resourcefulness. The trait of resourcefulness was expressed by two of twelve leaders. One expressed how essential it was to be resourceful in how they implement the program. "While our program does have guidelines, you can only do this, this, and this, you can still make things work." This trait was rated the highest of all seven by the educators. It was a 4.26 on the 1 to 5 scale. Educators wrote, "Our unit leaders always look for ways to use resources wisely and always look for ways to save resources/ 
money," and "They want to make sure we have what we need to do our jobs while at the same time we need to use our resources wisely." One comment described what an educator thought to be an inappropriate use of time and resources from their perspective, "They are frequently making trips to bring us stuff, despite the fact someone who lives close or is making a trip nearby could make the trip and therefore claim less mileage and not waste our leadership's time."

Conservation. None of the twelve leaders interviewed expressed any leadership traits that were consistent with the sustainable leadership principle of conservation. The trait scored a moderate 3.37 on the Likert-type scale. The educators described, "In our unit, I think our leaders use their past experiences to help find solutions. I feel as extension as a whole we value our past and what has made this organization great" Another educator, although new, stated about their leader's conservation traits and valuing of the past, "I believe this is true. I haven't worked for FNEP for very long, but with what I have seen this is true."

One educator had a much more skeptical view of their leaders' valuing of the past:

They talk about things that happened in the past and how those people were "not doing their jobs". I also look at things that have happened in our region under their leadership and instead of them learning from those situations and being sure they don't happen again, they are turning a blind eye on some people meaning they didn't learn anything from their mistakes showing they clearly have no value in the past. 


\section{Research Question Two}

The second research question, "Is there a difference between the program administrators within the University of Missouri Extension's reported sustainable leadership practices and the paraprofessional educators' perceptions of their administrators' sustainable leadership practices?" was answered by comparing two pieces of data using a t-test. A t-test was used because it is the preferred analysis for determining a correlation between two independent variables (McDavid, Huse, \& Hawthorn, 2013). The two numbers being compared are the numerical values assigned to the leaders' sustainable leadership practices and the average scores of the paraprofessional educator survey asking their perceptions of their leaders' sustainable leadership practices. In order to determine significance, alpha $<0.5$ which is considered a standard for stringent data analysis (McDavid, Huse, \& Hawthorn).

By utilizing a t-test to determine if a correlation exists between these two variables, there is no significant relationship between the leaders reported sustainable leadership practices and the paraprofessional educators' perceptions of their administrators' sustainable leadership practices. The personal correlation is $-1.40, \mathrm{p}=.765$.

The researcher did not display these results in a table because they were not significant.

The educators' perceptions of their leaders use of sustainable leadership practices was higher than the leaders reported uses. The leaders were not directly asked about these seven practices during their individual interviews in order not to evoke bias in their answering. 


\section{Research Question Three}

The reported level of employee engagement of nutrition paraprofessional educators within the University of Missouri Extension nutrition programs is 4.49. According to the scale provided by the survey researchers, that is within the range of an average level of engagement (2.89-4.66). The average is across all seven regions surveyed. When the regions were looked at individually, two had scores considered "high," while the other five's scores were considered "average." Table 3 illustrates the average scores for all regions and each region individually. Region 4 and Region 6 had "high scores."

Table 3 Average UWES Scores

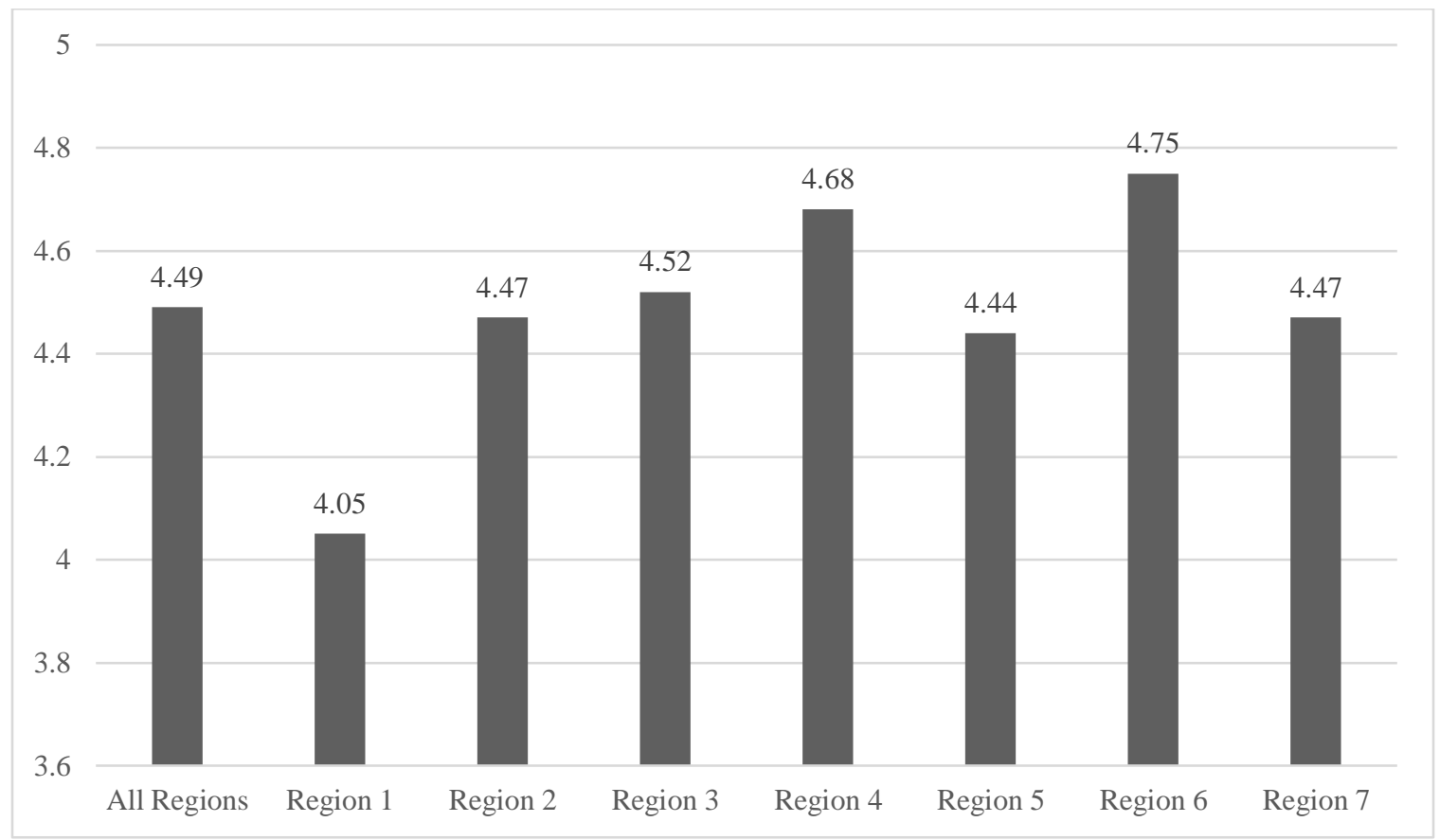

Note: $\mathrm{N}=63$

The range of scores was from 2.5 to 5.65 . The score of 2.5 is considered to be low, while the score of 5.65 is considered very high. The large range demonstrates how employee engagement can vary greatly among individuals, despite consistency in average 
scores between regions. The level of average to high level of engagement of educators is unsurprising. It is consistent with the existing research on motivation for nutrition educators. Perceived program value, supportive supervision, and autonomy were all positively related to job satisfaction, and pay was not the primary motivation for paraprofessional educators (Dickin, Dollahite, \& Habicht, 2011).

\section{Research Question Four}

The final research question answered "Is there a relationship between the level of sustainable leadership practices used by program administrators and employee engagement scores of nutrition paraprofessional educators?" Through the researcher's analysis, there is a positive correlation between the educators reported level of sustainable leadership practices by program administrators and employee engagement scores of nutrition paraprofessional educators. When all seven regions' responses were averaged, the Pearson correlation $=0.542$, with a $\mathrm{p}<.000$. These results are illustrated in Table 4. 
Table 4 Scatterplot of UWES and Sustainable Leadership Average Scores

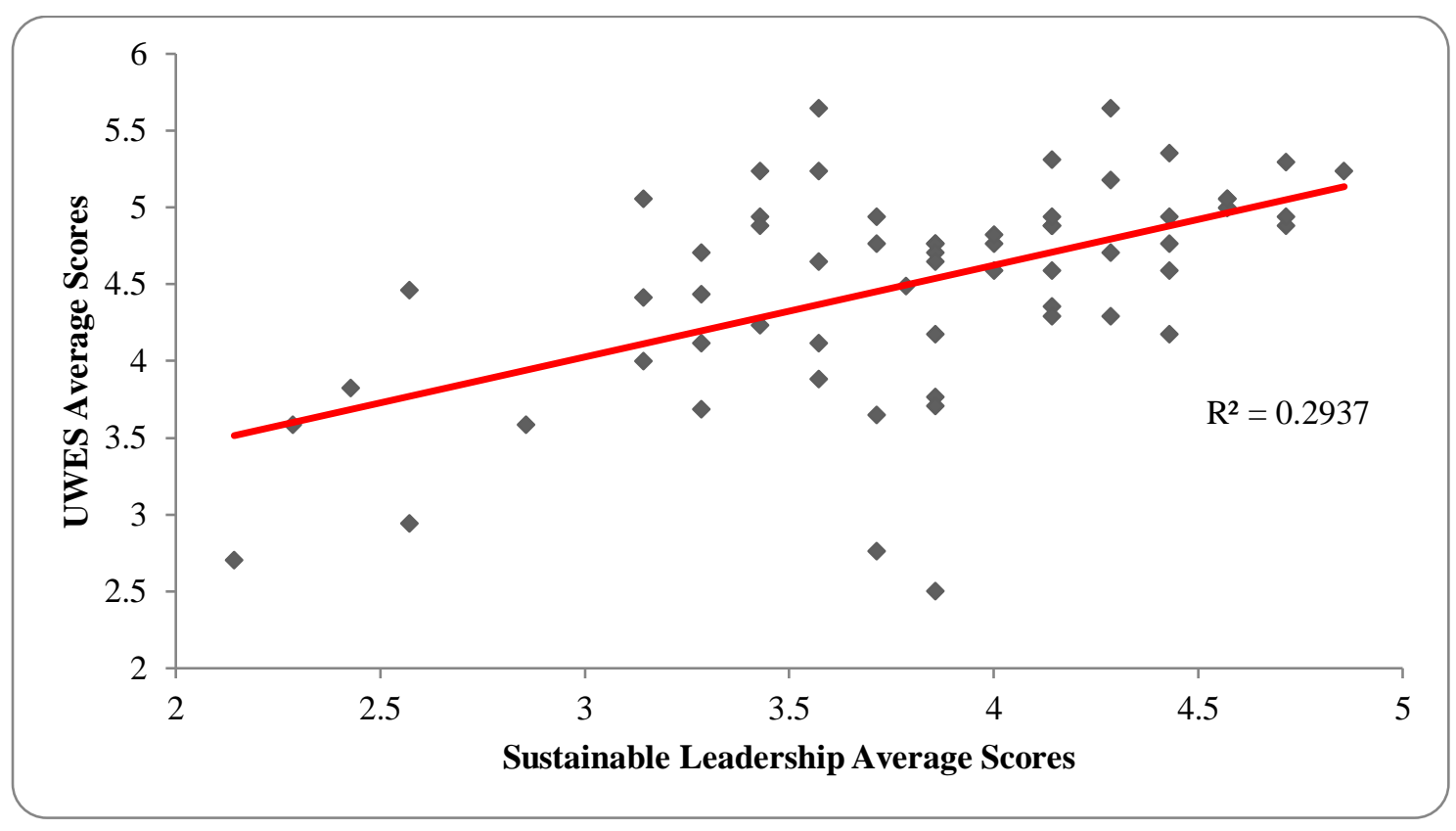

Note: $\mathrm{N}=62$

When the scores were separated by region, only two of seven regions had significant relationships. The lack of significant relationship among five of the seven regions could be because the sample size drastically diminishes when regions are separated. The average score across all educators speaks well to the program and the internal motivation of the educators to work on this program. This is consistent with existing research on motivation in public sector employees and within extension paraprofessional educators (Okello \& Gilson, 2015).

\section{Implications}

This section will detail what next steps could be taken to make program improvements based on the results of the study. These could include training for leadership and engagement, they also could include opportunities for research publications and research posters. These implications will extend beyond the program 
being studied, specifically noting how these efforts could be utilized in a broader way to impact other Extension nutrition programs and potentially other educational entities outside of this narrow frame.

Based on the results of the study, that there are sustainable leadership practices being utilized by program leadership and the positive relationship between sustainable leadership practices and employee engagement, more studies are called for to determine if this link continues to be true with additional research. Immediately, training and development related to sustainable leadership and the use of those practices in the University of Missouri Extension's nutrition programs could benefit the program. Although the correlation determined is not a causal relationship, implementing additional training and development for leaders could potentially have impacts on employee engagement, as well as other employee factors such as satisfaction, retention, and turnover. The research on employee engagement cites clear and convincing relationships between engagement and other employee outcomes (Harter, Schmidt, \& Hayes, 2002; May, Gibson, \& Harter, 2004).

There are multiple national meetings annually for extension nutrition programs. This research and future research could be presented in multiple forms, such as posters or presentations, in order to help all programs nationally implement leadership training and development geared toward improving employee engagement and potentially positively benefitting other employee outcomes, as well. These meetings are a great opportunity to reach all providers of SNAP-Ed and EFNEP programs nationally as attendance to national annual meetings is compulsory for all federally funded programs. 
These results and the results of future studies could not only have positive consequences for the University of Missouri's nutrition programs, but for all programs nationally. These long-standing programs operate in every state and U.S. territory and if positive relationships between leadership practices, employee engagement, and employee outcomes exist, all programs could benefit from happier and more effective employees, more retention and less turnover.

\section{Recommendations}

Based on the current research study, the researcher has several recommendations for the nutrition program studied. These recommendations include training for sustainable leadership practices, the creation of leadership core competencies, and practices to further enhance the educators' engagement.

\section{Recommendation One}

The first recommendation for the University of Missouri Extension's Family Nutrition Education Program is to provide leadership training for the administrators of the program. By using sustainable leadership as a guide, because of the findings of this study, it can help inform the training and guidance of leadership training following one set of leadership practices. The research study found both the leaders and educators in the program reported the use of sustainable leadership practices by FNEP program leaders. Additionally, because the study found a significant relationship between sustainable leadership practices and levels of educator engagement, this recommendation is to utilize the seven sustainable leadership practices as the foundation for leadership training and development for the leaders of MU Extension FNEP. 


\section{Recommendation Two}

This leadership and additional research on what leadership practices are being used and the relationships they have with educators' employee engagement and potentially program impacts, can be used to inform new policy to guide the nutrition programs at the University of Missouri Extension and other nutrition programs. National programs such as these thrive from standardization; it helps fundees communicate program value, with funders ensured their dollars are being used appropriately. These standards continue down to paraprofessional educators in the form of educator "Core Competencies" (“Core Competencies- EFNEP \& SNAP-Ed,” 2015). These competencies include expectations for teaching, reporting, and personal accountability. Furthermore, these programs import the value of standardization among programs both between and within states ("Core Competencies- EFNEP \& SNAP-Ed"). The existence of these competencies ensures these programs, including the paraprofessional educators, are standard in program and values. Utilizing the same rationale and philosophy as was used during the creation of paraprofessional educator core competencies, the existence of standards or core competencies for program leadership would also create standardization and clarity of roles among programs and in the case of Missouri, the local program coordinators serve as direct supervisors to the paraprofessional educators.

\section{Recommendation Three}

The final recommendation proposed by the researcher is to create practices from the leadership and programmatic level in order to increase educator engagement. Research shows clear links between employee engagement and employee outcomes such as retention, satisfaction, and turnover (Harter, Schmidt, \& Hayes, 2002; May, Gibson, \& 
Harter, 2004). A commitment to implementing strategies and practices in order to increase engagement could potentially have positive impacts on the educators and on the programs as a whole. Anecdotally, during the research process, the researcher observed after the interview with one of the leaders, the leader reached out to their employees and expressed their appreciation. One of those educators mentioned these efforts to the researcher and their appreciation. This one anecdote helps illustrate the immense impact efforts to increase employee engagement can have.

\section{Limitations and Direction for Future Research}

There are several limitations to the study. First, there are many SNAP-Ed and EFNEP programs and they are all operated differently based on their administrative expectations and this study is only capturing data from one program at one state. It will be difficult to generalize results to additional Extension nutrition programs based on this initial study (Cresswell, 2013). These principles can potentially still be of use to other programs, but they would individually have to consider their own program and how it functions (Cresswell). Limitations to this study also include the personal connection to the organization due to the researcher's employment (Merriam, 2009). The researcher is a project director of one of the eight geographic regions being studied. This potential bias has helped dictate the approach the researcher is taking to this study. The researcher excluded her region entirely, neither the leaders were interviewed nor the paraprofessional educators were surveyed. Additional limitations exist because only quantitative data via surveys is being collected from the paraprofessional educators and only qualitative data being collected from the program leaders. Due to the geographic distance and large numbers of paraprofessional educators, the researcher is restricted to 
quantitative data from the paraprofessional educators and because of the small sample size, the researcher is restricted to only collecting qualitative data from the leaders.

This research can have implications for the nutrition programs at the University of Missouri Extension and at other programs nationally. These findings could be the basis for more research on leadership practices and the impacts they have on the educators and the programs themselves. This and other future research could be used to inform policy. Because this study found significant relationships, future training and management practices can be adapted to incorporate these constructs. Continued research on desirable leadership practices could also help inform the creation of leadership "Core Competencies" (“Core Competencies- EFNEP \& SNAP-Ed,” 2015).

\section{Summary}

Despite the limitations of the current research study, the findings can be used to help create standards of practice for leaders of the Family Nutrition Education Programs at the University of Missouri Extension, as well as other national nutrition programs. The study revealed the use of sustainable leadership practices within MU Extension's FNEP program, average levels of employee engagement among the paraprofessional educators, and a significant relationship between the use of sustainable leadership practices and educators' levels of engagement. While limitations exist related to the limited scope of the current study and the generalizability of the findings, this study begins to establish a body of knowledge related to leadership and the impacts on employee engagement within community nutrition programs. 
SECTION FIVE

CONTRIBUTION TO SCHOLARSHIP 


\section{Karen Chapman-Novakofski, Editor-in-Chief,}

Please accept this article submission for review in the upcoming issue of Journal of Nutrition Education and Behavior. The attached article aligns with the journal's primary purpose of promoting effective nutrition education and healthy behavior. I want to assure you of the manuscripts fit with your journal's mission surrounding nutrition education and behaviors.

This submission provides an in depth look into leadership and employee engagement of the SNAP-Ed and EFNEP programs in one Midwestern state. Specifically, the article is based on a mixed-methods research design for the purpose of identifying the use of sustainable leadership practices, the level of employee engagement of paraprofessional educators, and determining if a relationship exists between the use of sustainable leadership practices and employee engagement.

Please review this submission as it adheres to the less than 4.500-word format request. Additionally, this article reviews current literature and adds to the body of knowledge surrounding the use of sustainable leadership practices and employee engagement in SNAP-Ed and EFNEP nutrition programs.

As the author, I served five years as one of the regional directors of the Missouri SNAP-Ed and EFNEP programs, the setting for the study and focus of the article submission. My research focus is to identify leadership practices that can have positive impacts on employee engagement and other potential positive programmatic outcomes. Thank you, Rachel L Gordon-Poff, Ed. D. 7903 Charlotte Street, Kansas City, MO 64131 RachelLGordon@gmail.com 
Title

An Initial Examination of Sustainable Leadership and Employee Engagement Within

Extension Nutrition Programs

Rachel L Gordon-Poff, Ed.D.

7903 Charlotte Street

Kansas City, MO 64131

(816) 213-2234

RachelLGordon@gmail.com 


\begin{abstract}
Nutrition programs operated by Cooperative Extension organizations seek to provide nutrition education to a low-income audience nationally. Research exists on the effectiveness of these programs, but gaps exist on the role of the leader and how their practices impact the educators and the programs as a whole. A transformative mixedmethods approach was used to capture both quantitative and qualitative data through a theoretical lens. Sustainable leadership and employee engagement were used as conceptual frameworks to ground this study. Open-ended interviews with twelve leaders of Extension nutrition programs were conducted. An online survey was distributed to 100 nutrition educators to determine their perceptions of their leaders' sustainable leadership practices and also a personal employee engagement inventory. The analysis of these interviews and surveys found that both the leaders and the educators reported the use of sustainable leadership practices being utilized by program leaders.

The qualitative portion of the study revealed six of the seven leadership traits were described by the leaders during their interviews. Also, there was no significant relationship between the reported levels of sustainable leadership practices by the leaders and the educators. From the employee engagement inventory, the educators of the extension nutrition program averaged an average level of employee engagement. Lastly, there was a significant positive relationship between the use of sustainable leadership and educator employee engagement. The use of sustainable leadership and the relationship between employee engagement can have implications for these programs nationally. This and future research on leadership and its impact on employee engagement can help inform policy and practice within national nutrition programs.
\end{abstract}




\section{Introduction}

University Extension nutrition programs are far-reaching programs, with federal guidance dictating program direction and acceptable activities ("The History of SNAP," 2015; United States Department of Agriculture, 2013). These national standards provide some opportunity for flexibility for individual programs, but program priorities and focus areas follow the expected practice guidelines. National programs thrive from standardization; this helps fundees communicate program value with funders to ensure their dollars are being used appropriately.

The purpose of this research study is to determine which sustainable leadership practices program coordinators within SNAP-Ed and EFNEP nutrition programs are using to manage and lead paraprofessional educators and to determine the level of engagement nutrition paraprofessional educators are experiencing within the workforce. Employee engagement is being utilized as the variable to evaluate the impact these practices have on paraprofessional educators (Kahn, 1990). Additionally, this study seeks to understand if a connection exists between the use of sustainable leadership practices and employee engagement.

Similarly, this study seeks to fill a gap in the existing research on Extension nutrition programs. Literature of these programs covers many areas: the paraprofessional educators, program effectiveness, and even the type of information collected from the participants (Dickin, Dollahite, \& Habict, 2010; Dickin, Dollahite, \& Habict, 2011;

Okello \& Gibson, 2015). A gap exists in the literature, however, in a significant study of the leaders, what practices they use, and how they impact the paraprofessional educators and the program. 
The University of Missouri Extension's Family Nutrition Education Programs were as the setting to complete this study. Similar programs exist nationwide, the University of Missouri is being used because the researcher had access to conduct the study at this location. The program is divided into eight geographic regions and they will each be studied so the data can be examined as a whole and separated by geographic region. In order to guide this study, the researcher proposes a host of questions to inform the study's constructs: sustainable leadership and employee engagement.

\section{Research Questions}

The research questions guiding this study are:

1. Do the leadership practices of program administrators within the University of Missouri Extension align with Sustainable Leadership principles?

2. Is there a difference between the program administrators within the University of Missouri Extension's reported sustainable leadership practices and the paraprofessional educators' perceptions of their administrators' sustainable leadership practices?

3. What is the reported level of employee engagement of nutrition paraprofessional educators within the University of Missouri Extension nutrition programs?

4. Is there a relationship between the level of sustainable leadership practices used by program administrators and employee engagement scores of nutrition paraprofessional educators? 


\section{Conceptual/Theoretical Framework}

In order to fully realize and provide the framework necessary to understand this study and its meaningfulness, two separate frameworks are presented: sustainable leadership (Hargreaves \& Fink, 2006) and employee engagement (Kahn, 1990).

Sustainable leadership. For the purpose of this study, sustainable leadership will be used to provide understanding and analysis of the leaders' behaviors because it identified seven distinct principles; these principles can be easily understood, researched, and applied to the nutrition program leaders. It was also the only theory to emphasize diversity or longevity (Northouse, 2013).

Hargreaves and Fink (2006) introduced seven principles of sustainable leadership. The seven principles of sustainable leadership are depth, length, breadth, justice, diversity, resourcefulness, and conservation (Hargreaves \& Fink). These seven principles interacting together is what provides uniqueness to this theory. At the core of an engaged workforce is the sustainable leader (Galpin \& Whittington, 2012).

Employee engagement. The use of employee engagement as an additional conceptual framework helps ground the use of the leadership practices in an understanding of outcomes for nutrition paraprofessional educators. Kahn's (1990) theory was chosen for the purpose of this study because it the most theoretically rich, examining the psychological aspects of employee engagement while the other two theories both operationalize engagement as the opposite of burnout.

Kahn (1990) defined personal engagement "as the harnessing of organization members' selves to their work roles; in engagement, people employ and express themselves physically, cognitively, and emotionally during role performances" (p. 694). 
Kahn's theory of employee engagement examined personal engagement and personal disengagement through the lens of three psychological facets: psychological meaningfulness, psychological availability, and psychological safety.

\section{Methods}

Transformative mixed methods was used for this study because it incorporates both qualitative and quantitative research through a theoretical lens (Cresswell, 2013). The quantitative and qualitative data collection occurred concurrently, which is consistent with the principles of this approach. Additionally, using mixed methods better helped the researcher triangulate the data and to balance the strengths of the quantitative and qualitative approaches against each other (Cresswell).

\section{Study Setting}

The setting used to answer the research questions was the eight geographic regions of the University of Missouri Extension's Family Nutrition Education Programs (FNEP). Each of the eight geographic regions has a two-person administrative unit, including a Project director and Program manager. They are responsible for training, curriculum, and overall program support to FNEP.

\section{Study Participants}

In order to answer the research questions, two types of participants were recruited. The first are those in the leadership position; both project directors and program managers were identified and asked to participate in a qualitative interview. These were conducted either in-person or via videoconference. All but one leader agreed to participate, the sample size is seven project directors $(\mathrm{n}=7)$ and five program managers $(n=5)$. 
The second set of participants was current paraprofessional educators. An email listserv exists of all current paraprofessional educators employed at the University of Missouri Extension FNEP. This included 100 employees. The survey received 64 responses, a response rate of $63.4 \%$. This purposeful sampling was done for two reasons. The first was convenience; the researcher had easy access to conduct an online survey on all of these participants. Secondly, because of the structure of the organization, they all share the same job title and can easily be used to compare against their respective supervisors, who also all have the same job title (Creswell, 2013; Merriam, 2009).

\section{Data Collection}

A mixed-method design was used in order to capture in-depth data from the leaders and to triangulate the data to the paraprofessional educators they manage (Creswell, 2013). Two distinct strategies for data collection were used. To collect data on what leadership practices are being used and if they relate to sustainable leadership principles, a qualitative interview was conducted with each leader. These semi-structured interviews lasted between 30-60 minutes and were conducted either in-person or via videoconference. All participants signed an informed consent (Appendix A). The questions asked were open-ended, asking each leader to reflect specifically on their general leadership philosophies and specific examples of their use of leadership practices (Appendix B).

The second data collection was the use of an electronic survey sent to the current listserv of nutrition paraprofessional educators. Survey responses were anonymous; no identifying information was collected. The survey opened with an informed consent statement (Appendix A). It only asked the participants to identify in which of the eight 
geographic regions they work. The survey consisted of two parts. The first was an employee engagement inventory. The employee engagement inventory was the Utrecht Work Engagement Scale (UWES), which consists of 17 items to measure employee engagement (Appendix B). This is the most widely used Employee engagement survey; it has been tested for reliability and validity in its many uses in research studies (Schaufeli, Bakker, \& Salanova, 2006; Schaufeli \& Bakker, 2003). Additionally, the survey sent to paraprofessional educators included a series of questions determining their perception of their program administrators' use of the seven sustainable leadership practices (Appendix B). This second portion of the survey was created by the researcher to add an additional point of analysis in order to determine if leaders' reported practices are consistent with the paraprofessional educators' perceptions of these same practices. It consisted of seven questions on a Likert-type scale asking the paraprofessional educators' perceptions of the sustainable leadership practices utilized by their region's administrators. Each question had a short-answer follow-up allowing the paraprofessional educator to give an example of a time this behavior was either utilized or not.

\section{Data Analysis}

Initially, the qualitative interviews were transcribed for ease of data analysis. The conceptual framework of sustainable leadership was used as the coding themes because it has already been established. Once the coding was complete, in order to conduct the later analyses, a numerical value was assigned to each of the eight administrative regions as well as an overall score for the entire program. Each administrative unit received a numerical score from 0 to 7 . For each of the seven sustainable leadership practices, one will be awarded for each of the seven practices the unit uses (could be either the Project 
director or the Program manager). For example, a unit identified both breadth and width as practices, received a score of 2 . Averaged scores ranged from 2 to 5 practices used per region. These seven scores were averaged to determine the average level of sustainable leadership practices across the entire program, average =3.6). Additionally, the paraprofessional educator responses to the 9-item questionnaire about their leaders' sustainable leadership practices was also used to provide information related to the research question. This first portion of the data analysis addresses the first research question, "Do the leadership practices of program administrators within the University of Missouri Extension align with Sustainable Leadership principles?”

The second research question, "Is there a difference between the program administrators within the University of Missouri Extension's reported sustainable leadership practices and the paraprofessional educators' perceptions of their administrators' sustainable leadership practices?" was answered by comparing two pieces of data using a t-test. A t-test was used because it is the preferred analysis for determining a correlation between two independent variables (McDavid, Huse, \& Hawthorn, 2013). The two numbers being compared are the numerical values assigned to the leaders' sustainable leadership practices and the average scores of the paraprofessional educator survey asking their perceptions of their leaders' sustainable leadership practices. In order to determine significance, alpha $<0.5$ which is considered a standard for stringent data analysis (McDavid, Huse, \& Hawthorn).

Then, the data collected from the paraprofessional educators was scored based on the Engagement Scale to determine employee engagement scores of each individual. Scores are calculated by adding all responses ( 1 to 6 ) and then dividing by the number of 
items (17) (Schaufeli, et al., 2006). Scores were averaged across all respondents and also amongst respondents from different geographic regions in order to provide a comparison point. Norm scores will be used to determine levels of employee engagement $($ Mean $=$ 3.74, SD=1.17). Very low (<1.78), Low (1.78-2.88), Average (2.89-4.66), High (4.675.50), Very High (>5.50) (Schaufeli, et. al). This will answer the third research question, "What is the level of employee engagement of nutrition paraprofessional educators within the University of Missouri Extension nutrition programs?"

The average engagement score from each region underwent a t-test to determine correlation (alpha <.05) against the sustainable leadership score of each region to answer the final research question, "Is there a relationship between the use of Sustainable Leadership practices by program administrators and Employee engagement scores of nutrition paraprofessional educators?" A t-test was because it is the preferred analysis for determining a correlation between two independent variables (McDavid, Huse, \& Hawthorn, 2013). Significance level was set at alpha $<.05$.

\section{Results and Discussion}

This section will present the results of the study, of the qualitative and quantitative analysis. The discussion will draw connections from the study results back to the theoretical and conceptual frameworks presented.

\section{Research Question One}

The first research question sought to answer the question, Do the leadership practices of program administrators within the University of Missouri Extension align with Sustainable Leadership principles? The researcher answered this question in two ways; first, by conducting interviews of leaders and collecting self-reported leadership 
practices, the second, by having educators complete a survey of their leader's leadership practices. All leaders identified between two and five of the sustainable leadership traits during their interviews. They were asked open-ended questions about their leadership philosophy and practices as not to create bias in answering by directly asking about the seven traits. Overall, six of the seven traits were utilized by at least one leader, conservation not being identified by any. Table one provides a ranking of the most utilized traits, as well as examples of each from the leaders' interviews.

Table 1 Ranking of Sustainable Leadership Traits

\begin{tabular}{lcl} 
Trait & Ranking & Example \\
\hline $\begin{array}{l}\text { Depth } \\
\text { box." }\end{array}$ & 1 & "I hope that I've gotten people to think outside the \\
$\begin{array}{l}\text { Breadth } \\
\text { program." }\end{array}$ & 1 & "Having a bigger picture view on the whole \\
Length & 3 & "Keep a similar model no matter what the change." \\
Justice & 3 & "Fair and consistent expectations for everybody." \\
Resourcefulness & 5 & "You can still make things work." \\
Diversity & 6 & "We have to be understanding of their needs." \\
Conservation & 7 &
\end{tabular}

Note: $\mathrm{n}=13$

The educators' perception of the use of sustainable leadership practices was collected via electronic survey. Short answer responses were gathered, as well as the average score for each trait on a 1 to 5 Likert-type scale from Strongly Disagree to Strongly Agree. The overall average across all seven sustainable leadership practices is 3.79. Overall, the responses indicate the paraprofessional educators somewhat agree with 
the use of sustainable leadership practices by their leaders. Table 2 illustrates the average scores and rankings across all seven leadership practices.

Table 2 Ranking of Sustainable Leadership Traits (from Employee Survey)

Trait

Ranking

Average Score (1 to 5)

\begin{tabular}{lll} 
Resourcefulness & 1 & 4.26 \\
Diversity & 2 & 4.03 \\
Length & 3 & 3.98 \\
Justice & 4 & 3.84 \\
Breadth & 5 & 3.61 \\
Depth & 6 & 3.40 \\
Conservation & 7 & 3.37 \\
\hline Note: $\mathrm{n}=63$ &
\end{tabular}

Depth. Five leaders verbalized the trait of depth during their interviews. One explained, "I hope that I've gotten people to think outside the box, also pushed people to places they weren't comfortable going. . . I don't think people necessarily like me for it, I hope that people have grown from it, the unit has grown from it." Additionally, another leader stated, "We need to be practicing what we are preaching. If we don't do what we are expecting other people to do, then they are not going to see us as viable resources."

The educators' survey responses rated the trait of depth at 3.40 on a Likert-type scale of 1 to 5. Examples of this trait provided include, "Our director has always provided training when new changes are put in place to make sure that the new information is fully understood," and "The director took time to explain why these changes were essential and worked with us to make sure we understood and answered any questions we had. 
She continually follows up and keeps us all on the same page." Additionally, one educator described their leader not utilizing the trait of depth as "It seems that our leaders talk about implementing a change but they never follow through with that implementation."

Length. The trait of length was articulated by three of the twelve leaders interviewed. One described how they implement this trait as:

I like to give my staff a head's up and kind of prepare them for change as I can. Whether that's this past week in a staff training and discussing these are things you might see coming in the next couple of weeks or if it's an email, you know briefly mention something they can expect so these things don't feel like big shocks, but feel like something they are more prepared for.

Additionally, another leader discussed how they implement their leadership consistently over time. "I came to that philosophy by just, every year has been different year to year, trying to keep a similar model no matter what the change or whatever it is."

The trait of length scored at 3.61 from the educator survey. One educator articulated how they felt their leader had implemented leadership that would be consistent in a transition. "I believe that my leader has things in good running order and that anyone following would transition well." Conversely, another educator aired grievances related to how the system operates. "I think that the Extension system runs extremely slow. The downtime between decisions (whether hiring related or otherwise) seems to be when negative consequences occur ... and the system continues to move extremely slow in resolving the issues that were created." 
Breadth. Breadth was identified by five leaders as a trait they use to describe their leadership style. One leaders explained their leadership as "A lot of open communication, a balance of discipline, flexibility, and just having a bigger picture view on the whole program. What we are doing here, what we are doing at the state." Also, another leader placed emphasis broadly on the mission of the organization, "I feel like you have to understand our mission, you have to really understand what we're trying to do."

The trait of breadth was rated as a 3.98 out of 5 by the educator survey. The short answer section included the following description of this trait. "When conflicts have arose, our leaders listen to all sides of the store and look for the best solution for all." Also, one educator described an action their leader takes while implementing change, "When change takes place, our leaders explain the changes and why they are essential. So, thoughtful and deliberate could be good describing words." Not all educator responses were positive. Once described rash action as "Reacts to what may be happening from campus. Starts implementing policy before a final decision has been made. In a lot of cases we have to take a step backwards because she changed things before a final decision was made."

Justice. Three different leaders expressed the understanding of justice as important in their leadership practices. One leader verbalized what they believed to be essential to leadership as having "Courage to make decisions ... having integrity, honesty ... being somebody that others can rely on and know that you will be truthful with them and that you will do what you say you will do." Another leader gave the example of "always having fair and consistent expectations for everybody." 
The sustainable leadership trait of justice had an average score of 3.84 on the educators' survey. They described their leaders' use of justice was "They always want to follow FNEP procedures. They want everyone to do their best just as they do themselves" and "I think we are all human and that our leaders are intentional and thoughtful most of the time with decision making." Although not all the comments viewed their leaders positively related to justice. "They always mention that a situation/decision is fair to the group as a whole... not sure that it always falls where everyone is treated equally however."

Diversity. Diversity was only identified by one leader in their description of their prescribed leadership philosophy. They explained, "I think we work with a diverse group of women so we have to be understanding of their needs and their preferences, their learning styles and their working styles."

Although diversity was only articulated by one leader, it scored highly on the educators' surveys, a 4.03 on a 1 to 5 scale. One educator described actions taken by their leader as, "They encourage those members of our office from a different culture to share with the office during meetings, etc." Another educator acknowledged the diversity of their unit and the acceptance from their leaders, "We have a rather diverse group. They are willing to accept us all with our strengths and weaknesses." While, one educator said this about diversity in their geographic unit, "I just don't think it comes up very often in our area."

Resourcefulness. The trait of resourcefulness was expressed by two of twelve leaders. One expressed how essential it was to be resourceful in how they implement the program. "While our program does have guidelines, you can only do this, this, and this, 
you can still make things work." This trait was rated the highest of all seven by the educators. It was a 4.26 on the 1 to 5 scale. Educators wrote, "Our unit leaders always look for ways to use resources wisely and always look for ways to save resources/ money," and "They want to make sure we have what we need to do our jobs while at the same time we need to use our resources wisely." One comment described what an educator thought to be an inappropriate use of time and resources from their perspective, "They are frequently making trips to bring us stuff, despite the fact someone who lives close or is making a trip nearby could make the trip and therefore claim less mileage and not waste our leadership's time.”

Conservation. None of the twelve leaders interviewed expressed any leadership traits that were consistent with the sustainable leadership principle of conservation. The trait scored a moderate 3.37 on the Likert-type scale. The educators described, "In our unit, I think our leaders use their past experiences to help find solutions. I feel as extension as a whole we value our past and what has made this organization great" Another educator, although new, stated about their leader's conservation traits and valuing of the past, "I believe this is true. I haven't worked for FNEP for very long, but with what I have seen this is true."

One educator had a much more skeptical view of their leaders' valuing of the past:

They talk about things that happened in the past and how those people were "not doing their jobs". I also look at things that have happened in our region under their leadership and instead of them learning from those situations and being sure they don't happen again, they are turning a blind eye on some people meaning 
they didn't learn anything from their mistakes showing they clearly have no value in the past.

\section{Research Question Two}

The second research question, "Is there a difference between the program administrators within the University of Missouri Extension's reported sustainable leadership practices and the paraprofessional educators' perceptions of their administrators' sustainable leadership practices?" was answered by comparing two pieces of data using a t-test. A t-test was used because it is the preferred analysis for determining a correlation between two independent variables (McDavid, Huse, \& Hawthorn, 2013). The two numbers being compared are the numerical values assigned to the leaders' sustainable leadership practices and the average scores of the paraprofessional educator survey asking their perceptions of their leaders' sustainable leadership practices. In order to determine significance, alpha $<0.5$ which is considered a standard for stringent data analysis (McDavid, Huse, \& Hawthorn).

By utilizing a t-test to determine if a correlation exists between these two variables, there is no significant relationship between the leaders reported sustainable leadership practices and the paraprofessional educators' perceptions of their administrators' sustainable leadership practices. The personal correlation is $-1.40, \mathrm{p}=.765$.

The researcher did not display these results in a table because they were not significant.

The educators' perceptions of their leaders use of sustainable leadership practices was higher than the leaders reported uses. The leaders were not directly asked about these seven practices during their individual interviews in order not to evoke bias. 


\section{Research Question Three}

The third research question was, "What is the reported level of employee engagement of nutrition paraprofessional educators within the University of Missouri Extension nutrition programs? The reported level of employee engagement of nutrition paraprofessional educators within the University of Missouri Extension nutrition programs is 4.49 . According to the scale provided by the survey researchers, that is within the range of an average level of engagement (2.89-4.66). The average is across all seven regions surveyed. When the regions were looked at individually, two had scores considered "high," while the other five's scores were considered "average." Table 3 illustrates the average scores for all regions and each region individually. Region 4 and Region 6 had "high scores."

Table 3 Average UWES Scores

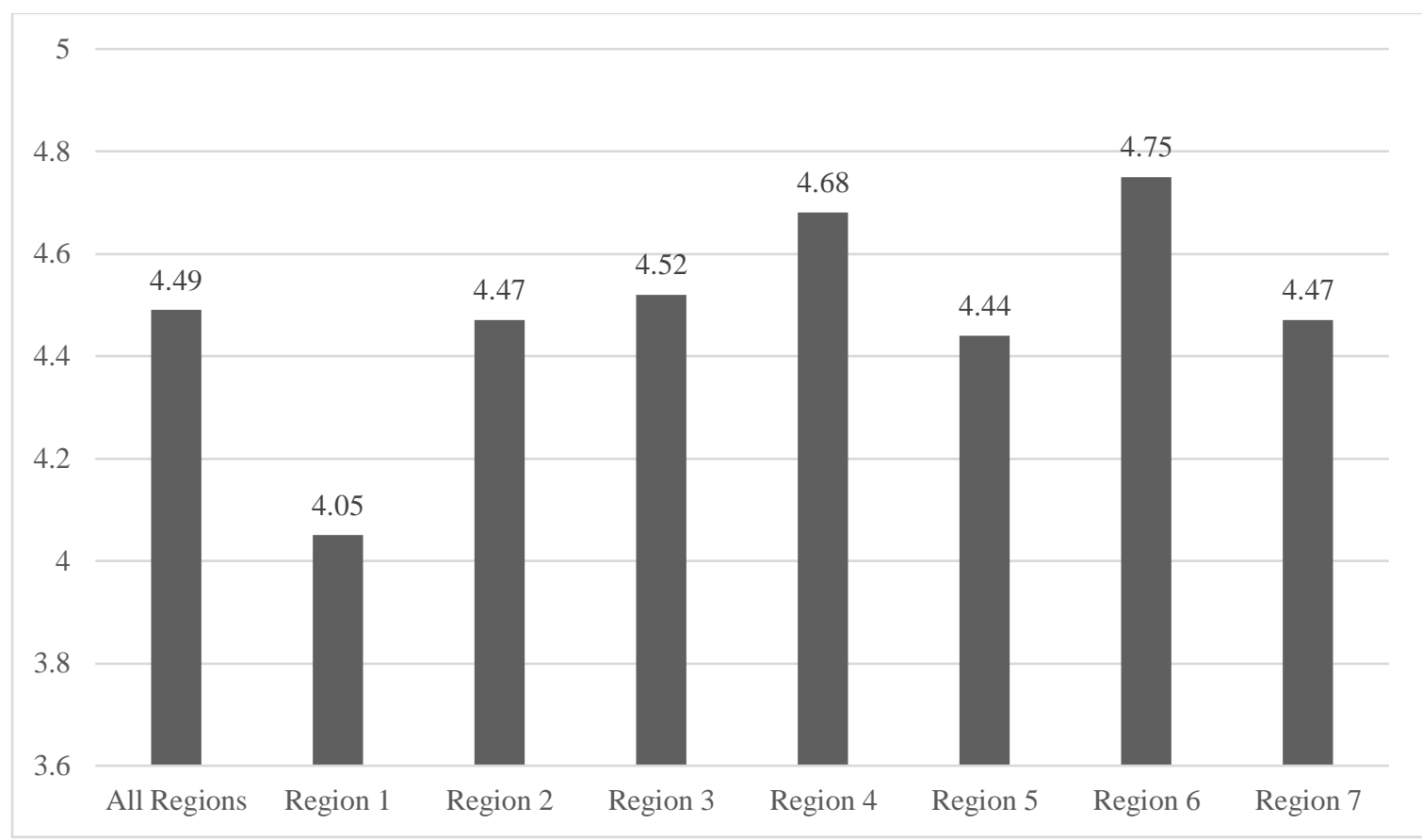

Note: $\mathrm{N}=63$ 
The range of scores was from 2.5 to 5.65 . The score of 2.5 is considered to be low, while the score of 5.65 is considered very high. The large range demonstrates how employee engagement can vary greatly among individuals, despite consistency in average scores between regions. The level of average to high level of engagement of educators is unsurprising. It is consistent with the existing research on motivation for nutrition educators. Perceived program value, supportive supervision, and autonomy were all positively related to job satisfaction, and pay was not the primary motivation for paraprofessional educators (Dickin, Dollahite, \& Habicht, 2011).

\section{Research Question Four}

The final research question answered "Is there a relationship between the level of sustainable leadership practices used by program administrators and employee engagement scores of nutrition paraprofessional educators?" Through the researcher's analysis, the answer is that there is a positive correlation between the educators reported level of sustainable leadership practices by program administrators and employee engagement scores of nutrition paraprofessional educators. When all seven regions' responses were averaged, the Pearson correlation $=0.542$, with a $p<.000$. These results are illustrated in Table 4. 
Table 4 Scatterplot of UWES and Sustainable Leadership Average Scores

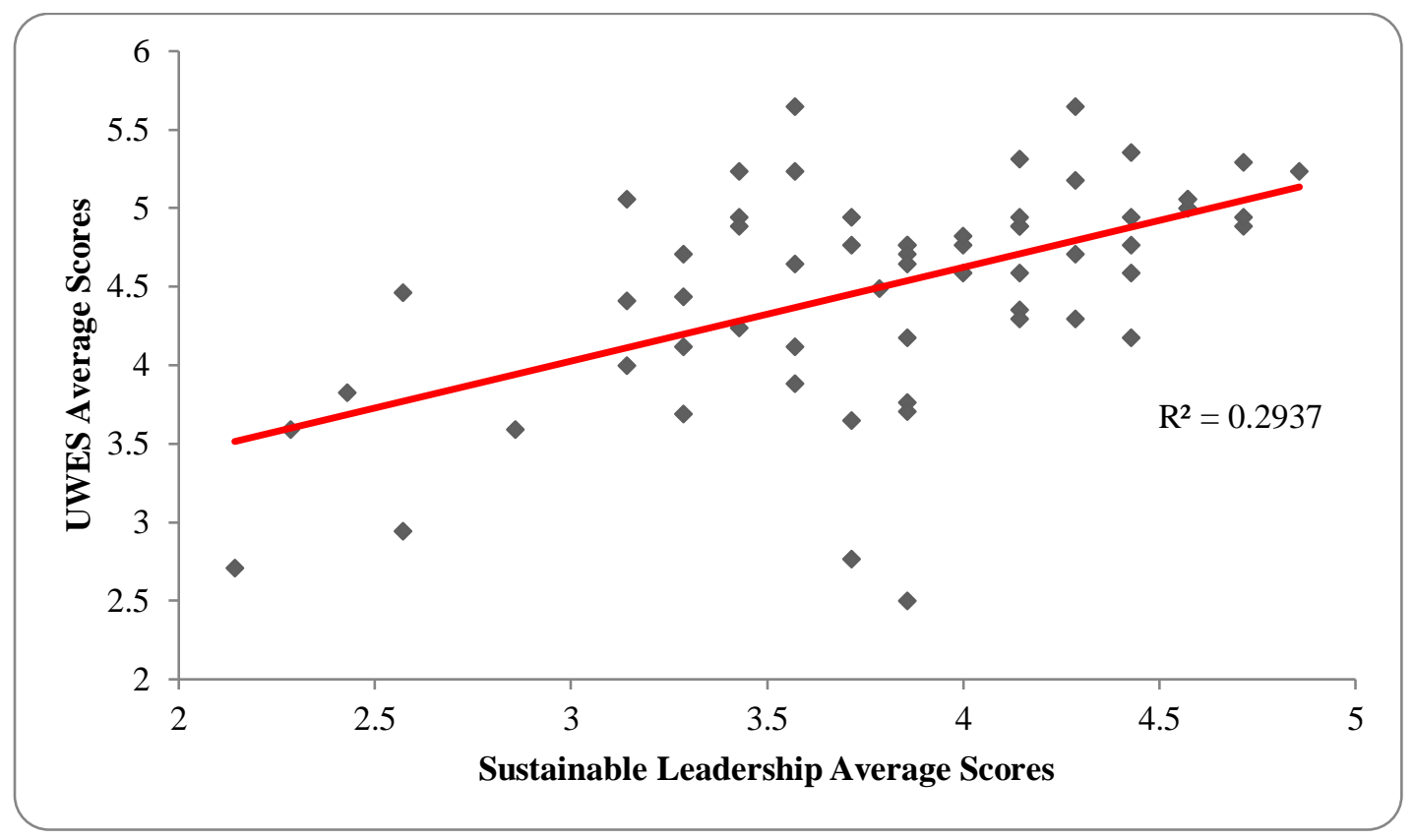

Note: $\mathrm{N}=62$

When the scores were separated by region, only two of seven regions had significant relationships. The lack of significant relationship among five of the seven regions could be because the sample size drastically diminishes when regions are separated. The average score across all educators speaks well to the program and the internal motivation of the educators to work on this program. This is consistent with existing research on motivation in public sector employees and within extension paraprofessional educators (Okello \& Gilson, 2015).

\section{Implications for Research and Practice}

Based on the results of the study, there are sustainable leadership practices being utilized by program leadership and the positive relationship between sustainable leadership practices and employee engagement, more studies are called for to determine if this link continues to be true with additional research. Immediately, training and 
development related to sustainable leadership and the use of those practices in the University of Missouri Extension's nutrition programs could benefit the program. Although the correlation determined is not a causal relationship, implementing additional training and development for leaders could potentially have impacts on employee engagement, as well as other employee factors such as satisfaction, retention, and turnover. The research on employee engagement cites clear and convincing relationships between engagement and other employee outcomes (Harter, Schmidt, \& Hayes, 2002; May, Gibson, \& Harter, 2004).

These results and the results of future studies could not only have positive consequences for the University of Missouri's nutrition programs, but for all programs nationally. These long-standing programs operate in every state and U.S. territory and if positive relationships between leadership practices, employee engagement, and employee outcomes exist, all programs could benefit from happier and more effective employees, more retention and less turnover. 


\section{Journal Article References}

Core competencies- EFNEP \& SNAP-Ed. 2015 Retrieved, from

http://nifa.usda.gov/resource/core-competencies-efnep-snap-ed

Creswell, J. W. (2009). Research design: Qualitative, quantitative, and mixed methods approaches. Los Angeles, CA: Sage.

Dickin, K., \& Dollahite, J., \& Habicht, J. (2009). Community Nutrition Educators’ Work Attitudes: Job Satisfaction and Intention to Leave. Food and Nutrition Education in Communities, 9(1), 1-2.

Dickin, K. L., Dollahite, J. S., \& Habicht, J. (2010). Job satisfaction and retention of community nutrition educators: The importance of perceived value of the program, consultative supervision and work relationships. Journal of Nutrition Education Behavior, 42(5), 337-344.

Dickin, K. L., Dollahite, J. S., \& Habicht, J. P. (2011). Enhancing the intrinsic work motivation of community nutrition educators: how supportive supervision and job design foster autonomy. The Journal of Ambulatory Care Management, 34(3), 260-273.

Emerson, R. M., Fretz, R. I., \& Shaw, L. L. (2011). Writing ethnographic fieldnotes. Chicago, IL: University of Chicago Press.

Galpin, T., \& Lee Whittington, J. (2012). Sustainability leadership: From strategy to results. Journal of Business Strategy, 33(4), 40-48.

Hargreaves, A., \& Fink, D. (2004). The seven principles of sustainable leadership. Educational Leadership, 61(7), 8-13.

Hargreaves, A., \& Fink, D. (2006). Sustainable leadership. San Francisco, CA: JosseyBass. 
Hargreaves, A. (2007). Sustainable leadership and development in education: Creating the future, conserving the past. European Journal of Education, 42(2), 223-233.

Harter, J. K., Schmidt, F. L., \& Hayes, T. L. (2002). Business-unit-level relationship between employee satisfaction, employee engagement, and business outcomes: a meta-analysis. Journal of Applied Psychology, 87(2), 268-279.

Kahn, W. A. (1990). Psychological conditions of personal engagement and disengagement at work. Academy of Management Journal, 33, 692-724.

May, D. R., Gilson, R. L., \& Harter, L. M. (2004). The psychological conditions of meaningfulness, safety and availability and the engagement of the human spirit at work. Journal of Occupational and Organizational Psychology, 77(1), 11-37.

McDavid, J. C., Huse, I., \& Hawthorn, L. R. (2013). Program evaluation and performance measurement: An introduction to practice (2 ed.). Los Angeles, CA: SAGE.

Merriam, S. B. (2009) Qualitative research: A guide to design and implementation. San Francisco, CA: Jossey-Bass.

Northouse, P. G. (2012). Leadership: Theory and practice. Los Angeles, CA: Sage.

Okello, D. R., \& Gilson, L. (2015). Exploring the influence of trust relationships on motivation in the health sector: a systematic. Human Resources for Health 13(16), 1-18.

Schaufeli, W.B. (2013). What is engagement? In C. Truss, K. Alfes, R. Delbridge, A. Shantz, \& E. Soane (Eds.), Employee Engagement in Theory and Practice. London: Routledge.

Schaufeli, W. B., Bakker, A. B., \& Salanova, M. (2006). The measurement of work engagement with a short questionnaire a cross-national study. Educational and 
Psychological Measurement, 66(4), 701-716.

Schaufeli, W. B., \& Bakker, A. B. (2003). Test manual for the Utrecht Work Engagement Scale. Unpublished manuscript, Utrecht University, the Netherlands. Retrieved from http://www.schaufeli.com

The history of SNAP. 2015. Retrieved, from http://www.snaptohealth.org/snap/thehistory-of-snap/

United States Department of Agriculture. (2013). The expanded food and nutrition education program policies. Washington, DC: NIFA Program Leadership.

Visser, W., \& Courtice, P. (2011). Sustainability leadership: linking theory and practice. Available at SSRN 1947221. 


\section{SECTION SIX}

SCHOLARLY PRACTITIONER REFLECTION 


\section{Scholarly Practitioner Reflection}

The dissertation process has been illuminating in finding ways to explain and better understand what I experience daily as a leader. Researching leadership practices, interviewing my peers to articulate the kind of leadership philosophy they prescribe to, and determining the level of employee engagement of the educators has asked me to confront and evaluate my own leadership, both philosophically and in practice. It has also challenged me to become the kind of leader I want to be. Through this dissertation process, a natural self-reflection occurred to the point of discomfort. Only then have I been able to understand the areas I need to work on. I have gained many skills from the EDD program, some I am sure I am not yet aware. I now have the understanding of my skills and my capabilities. Now that I have the research and the literature on leadership to support my first-hand experience, I know I am up for any challenge that comes my way. This process and the EDD program as a whole has given me confidence in the skills I already knew I possessed, but helped me find my voice by providing tools and the capacity to put into practice the things I've learned.

I have also discovered and learned through the data collection process and writing up the findings. One result I personally found striking during this process was the lack of consideration for issues of diversity articulated in the leadership interviews. This particular facet was so important to me as a leader within Extension. It was a considered factor in many decisions and strategies such as hiring, program coverage and need, as well as training. Although my colleagues may also value diversity, but I struggle to understand how if it is valued, it would not appear in a leadership interview. As a leader, I view it as my responsibility to lead the charge and set an example for diversity in all aspects of the program. The continuation of a diverse work environment relies on a 
commitment to recruit and retain diverse employees, but also can be attributed to educational policies that have supported the further education of minority groups. Educational policy is deeply rooted in equity issues. Many pieces of legislation, especially since 1950, have focused on creating access and opportunity for all. According to Mitchell, Crowson, and Shipps (2011), "among the most hard-fought and controversial educational policy issues agonizing public education in the United States over the past 60 years has been securing equal rights and equal educational opportunities for individuals and social groups" (p. 119). Creating paths for representation for all people, and having diversity represented are fundamental to an equitable and ethical educational system and workforce.

Additionally, as the results of the employee engagement survey revealed that the educators within the program are engaged. I have reflected on the important role the required monthly in-service trainings play in maintaining and growing that engagement. These trainings also serve an essential function of encouraging and maintaining employee motivation. Acknowledging the intersections of adult learning motivation and diversity is essential in ensuring that training and support is appropriate and beneficial for all. Successful motivation requires a comprehensive understanding of how individuals are motivated. Merriam and Bierema (2014) discussed three distinct types of learning motivation. "Goal-oriented learners engage in learning as a means to attaining another goal" (p.151), "activity-oriented learners participate for the opportunity to socialize with other learners and for the sake of the activity" (p. 151), and "learning-oriented learners are focused on developing new knowledge for the sake of learning" (p. 151). These three distinct types of learners are important to consider in planning and creating training 
content. Content must be applicable to their duties, but presented in a manner that can be absorbed by all. There are educators on my team that embody these three different styles and this understanding can not only help me plan for the future, but understand why things from the past have been received well by different people.

Before I embarked on this dissertation path, I would have described myself as an authentic leader. I believed whole-heartedly that having a "true north" and an intrinsic set of values that guide behaviors and decision-making was essential. Although I still believe these factors are essential and I value them highly personally, I think striving to embody the seven principles of sustainable leadership is essential not only for my own leadership practices, but for the bigger picture. During the process of this dissertation, I changed employers and no longer managing the team of paraprofessional educators I hired, trained, and developed. Leaving a position you value so highly is an emotionally taxing experience. As I was preparing for my departure, as well as during the transition, these traits created a clarity that was only possible because I had a new perspective. Facets such as conservation, which I had always struggled personally with, took on a new meaning. I was able to see myself as a small piece of a much larger puzzle. This program was successful before I was there and will continue to be successful long after my departure. And now as I settle into a new role, I am acutely aware of the importance of making decisions and actions that are for the long-term and consistent with the bigger picture, regardless of my own personal preferences.

I know undoubtedly that this program and this dissertation have challenged me in ways I had not expected and I became a better leader and a better scholar for them. I can 
proudly say that my Doctor of Education degree came from the Cooperative EDD program and it is very meaningful for me. 


\section{References}

Avery, G. C., \& Bergsteiner, H. (2011). Sustainable leadership practices for enhancing business resilience and performance. Strategy \& Leadership, 39(3), 5-15.

Bakker, A. B., \& Demerouti, E. (2007). The job demands-resources model: State of the art. Journal of Managerial Psychology, 22, 309-328.

Bolman, L. G., \& Deal, T. E. (2008). Reframing organizations: Artistry, choice, and leadership (4th ed.). San Francisco, CA: Jossey-Bass.

Boyatzis, R. E., Smith, M. L., \& Blaize, N. (2006). Developing sustainable leaders through coaching and compassion. Academy of Management Learning \& Education, 5(1), 8-24.

Core competencies- EFNEP \& SNAP-Ed. 2015 Retrieved, from http://nifa.usda.gov/resource/core-competencies-efnep-snap-ed

Crawford, E. R., LePine, J. A., \& Rich, B. L. (2010). Linking job demands and resources to employee engagement and burnout: a theoretical extension and meta-analytic test. Journal of Applied Psychology, 95(5), 834-848.

Creswell, J. W. (2009). Research design: Qualitative, quantitative, and mixed methods approaches. Los Angeles, CA: Sage.

Dickin, K., \& Dollahite, J., \& Habicht, J. (2009). Community Nutrition Educators’ Work Attitudes: Job Satisfaction and Intention to Leave. Food and Nutrition Education in Communities, 9(1), 1-2.

Dickin, K. L., Dollahite, J. S., \& Habicht, J. (2010). Job satisfaction and retention of community nutrition educators: The importance of perceived value of the 
program, consultative supervision and work relationships. Journal of Nutrition Education Behavior, 42(5), 337-344.

Dickin, K. L., Dollahite, J. S., \& Habicht, J. P. (2011). Enhancing the intrinsic work motivation of community nutrition educators: how supportive supervision and job design foster autonomy. The Journal of Ambulatory Care Management, 34(3), $260-273$

Emerson, R. M., Fretz, R. I., \& Shaw, L. L. (2011). Writing ethnographic fieldnotes. Chicago, IL: University of Chicago Press.

French, J. R. P., Jr. \& Raven, B. (2005). The bases of social power. In J. M. Shafritz, J. S. Ott, \& Y. S. Jang (Eds.), Classics of Organization Theory (6th ed., pp. 311-320). Belmont, CA: Wadsworth. (Reprinted from Studies in Social Power, pp. 370-396 by J. R. P. French, Jr. \& B. Raven, 1959, Ann Arbor, MI: Institute for Social Research, University of Michigan).

Galpin, T., \& Lee Whittington, J. (2012). Sustainability leadership: From strategy to results. Journal of Business Strategy, 33(4), 40-48.

Hargreaves, A., \& Fink, D. (2004). The seven principles of sustainable leadership. Educational Leadership, 61(7), 8-13.

Hargreaves, A., \& Fink, D. (2006). Sustainable leadership. San Francisco, CA: JosseyBass.

Hargreaves, A. (2007). Sustainable leadership and development in education: Creating the future, conserving the past. European Journal of Education, 42(2), 223-233. 
Harter, J. K., Schmidt, F. L., \& Hayes, T. L. (2002). Business-unit-level relationship between employee satisfaction, employee engagement, and business outcomes: a meta-analysis. Journal of Applied Psychology, 87(2), 268-279.

Hill, G. W. (1982). Group versus individual performance: Are N+ 1 heads better than one? Psychological bulletin, 91(3), 517.

History. 2016. Retrieved, from https://www.archivesfoundation.org/documents/smithlever-act-1914/

History of MU Extension. 2013. Retrieved, from http://extension.missouri.edu/about/history.aspx

History of the University of Missouri. 2016. Retrieved, from http://missouri.edu/about/history/history-mu.php

Kahn, W. A. (1990). Psychological conditions of personal engagement and disengagement at work. Academy of Management Journal, 33, 692-724.

Land-Grant University FAQ. 2016. Retrieved, from http://www.aplu.org/aboutus/history-of-aplu/what-is-a-land-grant-university/

Leon, M. R., Halbesleben, J. R., \& Paustian-Underdahl, S. C. (2015). A dialectical perspective on burnout and engagement. Burnout Research, 2(F2), 87-96.

Maslach, C., Schaufeli, W. B., \& Leiter, M. P. (2001). Job burnout. Annual Review of Psychology, 52, 397-422.

Maslow, A. H. (2005). A theory of human motivation. In J. M. Shafritz, J. S. Ott, \& Y. S. Jang (Eds.), Classics of Organization Theory (6th ed., pp. 167-184). Belmont, 
CA: Wadsworth. (Reprinted from Psychological review, pp. 370-396. By A. H. Maslow, 1943).

May, D. R., Gilson, R. L., \& Harter, L. M. (2004). The psychological conditions of meaningfulness, safety and availability and the engagement of the human spirit at work. Journal of Occupational and Organizational Psychology, 77(1), 11-37.

McDavid, J. C., Huse, I., \& Hawthorn, L. R. (2013). Program evaluation and performance measurement: An introduction to practice (2 ed.). Los Angeles, CA: SAGE.

McGregor, D. M. (1957). The human side of enterprise. Management Review, Nov. 1957, 41-49.

Merriam, S. B. (2009) Qualitative research: A guide to design and implementation. San Francisco, CA: Jossey-Bass.

Merriam, S. B., \& Bierema, L. L. (2013). Adult learning: Linking theory and practice. San Franciso, CA: Jossey-Bass.

Mintzberg, H. (2005). The five basic parts of the organization. In J. M. Shafritz, J. S. Ott, \& Y. S. Jang (Eds.), Classics of Organization Theory (6th ed., pp. 219-230). Belmont, CA: Wadsworth. (Reprinted from The structure of organizations: a synthesis of research, pp. 18-34. by H. Mintzberg, 1979, Upper Saddle River, NJ: Prentice Hall).

Mitchell, D. E., Crowson, R. L., \& Shipps, D. (2011). Shaping education policy. New York, NY: Routledge.

Morrill Act. 2016. Retrieved, from https://www.loc.gov/rr/program/bib/ourdocs/Morrill.html 
Northouse, P. G. (2012). Leadership: Theory and practice. Los Angeles, CA: Sage.

Okello, D. R., \& Gilson, L. (2015). Exploring the influence of trust relationships on motivation in the health sector: a systematic. Human Resources for Health 13(16), $1-18$.

Pfeffer, J. \& Salancik, G. R. (2005). External control of organizations: A resource dependence persepctive. In J. M. Shafritz, J. S. Ott, \& Y. S. Jang (Eds.), Classics of Organization Theory (6th ed., pp. 521-532). Belmont, CA: Wadsworth. (Reprinted from The external control of organizations, pp. 1-22. by J. Pfeffer \& G. R. Salancik, 1978, New York: Harper \& Row).

Roethlisberger, F. J. (2005). The Hawthorne experiments. In J. M. Shafritz, J. S. Ott, \& Y. S. Jang (Eds.), Classics of organization theory (6th ed., pp. 158-166). Belmont, CA: Wadsworth. (Reprinted from Management and morale, pp. 7-26. by F. J. Roethlisberger, 1941, Cambridge, MA: Harvard University Press).

Saks, A. M., \& Gruman, J. A. (2014). What do we really know about employee engagement? Human Resource Development Quarterly, 25(2), 155-182.

Schaufeli, W.B. (2013). What is engagement? In C. Truss, K. Alfes, R. Delbridge, A. Shantz, \& E. Soane (Eds.), Employee Engagement in Theory and Practice. London: Routledge.

Schaufeli, W. B., Bakker, A. B., \& Salanova, M. (2006). The measurement of work engagement with a short questionnaire a cross-national study. Educational and Psychological Measurement, 66(4), 701-716.

Schaufeli, W. B., \& Bakker, A. B. (2003). Test manual for the Utrecht Work Engagement Scale. Unpublished manuscript, Utrecht University, the Netherlands. Retrieved from http://www.schaufeli.com 
Smith-Lever Act of 1914. 2016. Retrieved, from

https://www.archivesfoundation.org/documents/smith-lever-act-1914/

The history of SNAP. 2015. Retrieved, from http://www.snaptohealth.org/snap/thehistory-of-snap/

United States Department of Agriculture. (2013). The expanded food and nutrition education program policies. Washington, DC: NIFA Program Leadership.

United States Department of Agriculture. (2016). Supplemental Nutrition Assistance Program Education Plan Guidance FY 2017. Washington, D.C.: Food and Nutrition Service.

Van den Broeck, A., Vansteenkiste, M., De Witte, H., \& Lens, W. (2008). Explaining the relationships between job characteristics, burnout, and engagement: The role of basic psychological need satisfaction. Work \& Stress, 22(3), 277-294.

Visser, W., \& Courtice, P. (2011). Sustainability leadership: linking theory and practice. Available at SSRN 1947221.

Walumbwa, F. O., Avolio, B. J., Gardner, W. L., Wernsing, T. S., \& Peterson, S. J. (2008). Authentic leadership: Development and validation of a theory-based measure†. Journal of management, 34(1), 89-126. 


\section{APPENDIX A}

Informed Consent

1. Gatekeeper Permission for Administrator and Educator Participation Letter

2. Gatekeeper Permission for Administrator and Educator Participation

3. Letter of Informed Consent - Educator Participant

4. Informed Consent from Leader Participant

Recruitment Script-Leader Participant 


\section{Gatekeeper Permission for Administrator and Educator Participation Letter University of Missouri Extension}

Dear <name>,

I would like to request your permission to invite applicable educators in your program to participate in a research study entitled: An Initial Examination of Sustainable Leadership and Employee Engagement within Extension Nutrition Programs. I am examining the reported leadership practices within the Family Nutrition Education Programs (FNEP) and the level of employee engagement for the educators within the program. Interviews will be coded to determine the extent their reported leadership practices align with Sustainable Leadership theory and if any relationship exists between sustainable leadership practices and levels of employee engagement. The information gathered should be beneficial to the Family Nutrition Education Programs and to other University Extension nutrition programs for informing leadership standards to encourage and promote employee engagement. This study is part of my dissertation research for a doctoral degree in Educational Leadership and Policy Analysis from the University of Missouri-Columbia.

For the study, Project Directors and Program Managers from each FNEP unit will be asked to complete a qualitative interview. Seven of the eight units will be asked to participate, Urban-West being excluded because that is the region I currently work in. Additionally, Nutrition Program Associates in the same seven regions will be asked to complete a Qualtrics survey, examining their level of employee engagement and their perceptions of their administrators' leadership practices. No personal or identifying information will be collected from these educators. I am seeking your permission as the administrator of the Family Nutrition Education Programs to contact the administrators and educators of FNEP for their participation in this study. A copy of the interview protocol and informed consent forms are attached for your review.

Participation in the study is completely voluntary. The participants may withdraw from participation at any time they wish without penalty, including in the middle of or after completion of the interview. Participants' answers will remain confidential, anonymous, and separate from any identifying information. The researcher will not list any names of participants in her dissertation or any future publications of this study.

Please do not hesitate to contact me with any questions or concerns about participation either by phone at (816) 213-2234 or by electronic mail at gordonra@ missouri.edu. In addition, you are also welcome to contact the dissertation advisor for this research study, Dr. Barbara Martin, who can be reached at 660-543-8823 or by email at bmartin@ucmo.edu.

If you choose to allow me to contact administrators and educators regarding participation in this study, please complete the attached permission form. A copy of this letter and your written consent should be retained by you for future reference.

Thank you for your time and consideration.

Sincerely,

Rachel Gordon-Poff

Doctoral Candidate 


\section{Gatekeeper Permission for Administrator and Educator Participation}

$\mathrm{I}$, , grant permission for

administrators and educators within the Family Nutrition Education Programs to be contacted to participate in the study An Initial Examination of Sustainable Leadership and Employee Engagement within Extension Nutrition Programs conducted by Rachel Gordon-Poff, doctoral candidate at the University of Missouri.

By signing this permission form, I understand that the following safeguards are in place to protect faculty choosing to participate:

- All participation is voluntary, and may be withdrawn at any point before culmination of the study.

- All responses will be used for dissertation research and for potential future journal publications.

- All identities will be kept confidential in all phases of the research.

- An interview will occur with each administrator either in-person or via videoconference, lasting approximately one hour in length.

- A survey to measure employee engagement will be sent to all FNEP educators using Qualtrics.

Please keep the consent letter and a copy of the signed consent form for your records. If you choose to grant permission for educators in your school district to participate in this study, please complete this Administrative Permission for Program Participation Form, please return it to Rachel Gordon-Poff as soon as possible.

I have read the material above, and any questions that I have posed have been answered to my satisfaction. I grant permission for administrators and educators in my program to be contacted and invited to participate in this study.

Signed:

Date:

Title/Position:

Institution:

Please return to: Rachel Gordon-Poff, 7903 Charlotte Street, Kansas City, MO 64131 Cell Phone: 816-213-2234 Email: gordonra@ missouri.edu 


\section{Letter of Informed Consent - Educator Participant}

You are being asked to participate in a research study entitled An Initial Examination of Sustainable Leadership and Employee Engagement within Extension Nutrition Programs which is being conducted by Rachel Gordon-Poff, a Project Director with MU Extension's Family Nutrition Education Programs. This survey is anonymous. No personal information will be asked and the survey platform Qualtrics will not collect any personal information. The survey should take 5 to 10 minutes to complete. Your participation is voluntary. You may choose not to take the survey, to stop responding at any time, or to skip any questions that you do not want to answer. Submission of the survey will be interpreted as your informed consent to participate.

If you have any questions about the research, please contact Rachel Gordon-Poff via email at gordonra@missouri.edu or the faculty advisor Dr. Barbara Martin at bmartin@ucm.edu . If you have any questions regarding your rights as a research subject, contact the MU Institutional Review Board (IRB) at (573) 882-3181.

Please print or save a copy of this page for your records. 


\section{INFORMED CONSENT FROM LEADER PARTICIPANT}

$\mathrm{I}$, , agree to participate in the

study An Initial Examination of Sustainable Leadership and Employee Engagement within Extension Nutrition Programs conducted by Rachel Gordon-Poff, doctoral candidate at the University of Missouri-Columbia. I understand the following:

My participation is voluntary, and may be withdrawn at any point before culmination of the study.

$\square$ My responses will be used for dissertation research and for potential future journal publications.

My identity will be kept confidential in all phases of the research.

$\square$ A interview will occur either in-person or via video conference at a mutually agreed upon time, lasting approximately 45 minutes to one hour in length.

Please keep the consent letter and a copy of the signed consent form for your records. If you choose to participate in this study, please complete the attached signed consent form, seal it in the enclosed envelope, and return to Rachel Gordon-Poff as soon as possible. Please to be sure and include contact information so interview plans can be made and communicated to you.

If you have any questions about the research, please contact Rachel Gordon-Poff via email at gordonra@missouri.edu or the faculty advisor Dr. Barbara Martin at bmartin@ucm.edu . If you have any questions regarding your rights as a research subject, contact the MU Institutional Review Board (IRB) at (573) 882-3181.

I have read the material above, and any questions that I have posed have been answered to my satisfaction. I voluntarily agree to participate in this study.

Signed: Date:

Title/Position:

\section{Contact Information:}

Phone (circle one) WORK HOME

CELL

Best time for contact:

E-mail:

Please return to: Rachel Gordon-Poff, 7903 Charlotte Street, Kansas City, MO 64131

Cell Phone: 816-213-2234 Email: gordonra@missouri.edu 


\section{Recruitment Script}

My name is Rachel Gordon-Poff, a doctoral candidate at the University of Missouri and a Project Director with MU Extension's Family Nutrition Education Program. I would like to invite you to participate in my research study to examine what leadership practices are being utilized by leaders within the Family Nutrition Education Programs. The study is entitled An Initial Examination of Sustainable Leadership and Employee Engagement within Extension Nutrition Programs.

As a participant, you will be asked to participate in an interview lasting 45 to 60 minutes. Your participation is entirely voluntary. You may skip any questions you do not want to answer.

If you would like to participate in this research study, please complete the provided consent form and return to me.

Do you have any questions now?

If you have questions later, please contact me at gordonra@missouri.edu or the faculty advisor Dr. Barbara Martin at bmartin@ucm.edu . 
APPENDIX B

Interview Protocol (Family Nutrition Education Program Leadership)

Work and Well-Being Survey (UWES)

Leadership Perceptions Survey 
Participating Leader:

Date:

Start Time:

Introduction:

Good afternoon. Thank you for taking the time to answer my questions focusing on your leadership practices and their relationship with employee engagement. My name is Rachel Gordon-Poff, and I will be conducting the interview. In order to ensure accuracy, I will be audio taping the interview.

Remember, there are no right or wrong answers. If you want to follow-up on a question or give an example, feel free to do that. I want this to be more of a conversation between professionals.

Our session will last about an hour and we will not be taking a formal break. Please let me know if you need to take a break for any reason. Let's begin.

\section{Questions}

Research Question(s)

Opening Questions: 5 min.

\begin{tabular}{|l|l|}
\hline 1. Tell me your name and your position within MU Extension. & $\begin{array}{l}\text { Learn about } \\
\text { participant }\end{array}$ \\
1. 2 . How long have you worked for the University of & \\
Missouri Extension? & \\
2. Have you held any other positions within MU Extension? & \\
If so, describe. & \\
\end{tabular}

Introductory Questions: 5-10 min. 
\begin{tabular}{|l|l} 
3. What do you think are important traits for a leader within & Q1, Q2
\end{tabular} FNEP?

Probes: Why do you think these traits are important?

Transition Question: 5-10 min.

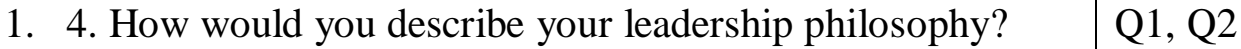

Probes: How did you come to hold this philosophy?

Why do you think this is the best leadership

philosophy?

2. Please describe how you put your leadership philosophy into practice.

Probes: Use specific examples

Key Questions: 10-15 min.

\begin{tabular}{|l|l|}
\hline 1. 5. How does your prescribed leadership philosophy impact & $\mathrm{Q} 4$ \\
your FNEP unit? & \\
Probes: Use specific examples & \\
2. How would you describe employee engagement? & \\
\hline
\end{tabular}

Key Questions: 10-15 min 


\begin{tabular}{|l|l|}
\hline $\begin{array}{l}\text { 1. What, if any, relationships do you think exist between } \\
\text { leadership and employee engagement? }\end{array}$ & Q4 \\
Probes: Why do you think this relationship exists? & \\
2. Do you think employee engagement can be improved? \\
Probes: What do you think would affect employee \\
engagement?
\end{tabular}

Ending Question: 5-10 min

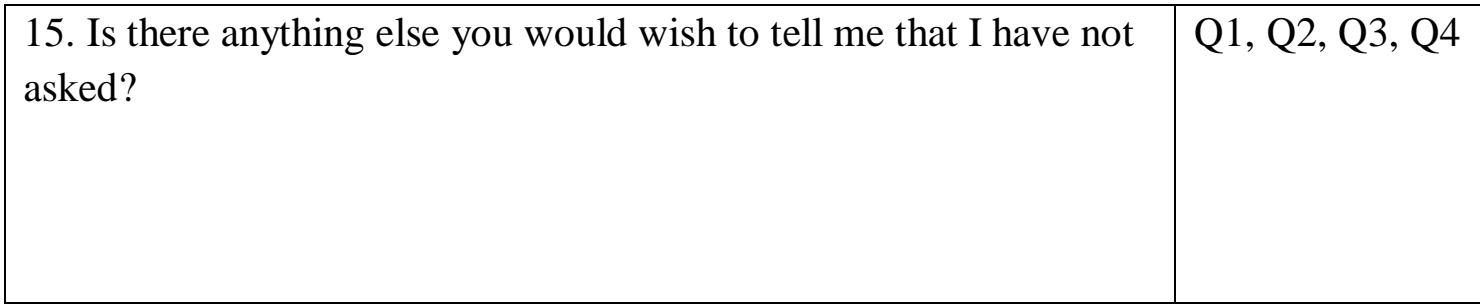

I would like to take this opportunity to thank you for your time and participation in this research project. When the research is completed, you will have the opportunity to read the results of the research. 


\section{Work \& Well-being Survey (UWES) (C)}

The following 17 statements are about how you feel at work. Please read each statement carefully and decide if you ever feel this way about your job. If you have never had this feeling, cross the '0' (zero) in the space after the statement. If you have had this feeling, indicate how often you feel it by crossing the number (from I to 6) that best describes how frequently you feel that way.

\begin{tabular}{ccccccc}
\hline & Almost never & Rarely & Sometimes & Often & Very often & Always \\
0 & 1 & 2 & 3 & 4 & 5 & 6 \\
Never & $\begin{array}{c}\text { A few times a } \\
\text { year or less }\end{array}$ & $\begin{array}{c}\text { Once a month } \\
\text { or less }\end{array}$ & $\begin{array}{c}\text { A few times a } \\
\text { month }\end{array}$ & Once a week & $\begin{array}{c}\text { A few times a } \\
\text { week }\end{array}$ & Every day \\
\hline
\end{tabular}

$$
1 .
$$
At my work, I feel bursting with energy* (VII)

2. I I I find the work that I do full of meaning and purpose (DEI)

3. _ Time flies when I'm working $(A B I)$

4. __ At my job, I feel strong and vigorous (VI2)*

5. I I am enthusiastic about my job $(D E 2)^{*}$

6. When I am working, I forget everything else around me (AB2)

7. _ـ My job inspires me (DE3)*

8. When I get up in the morning, I feel like going to work (VI3)*

9. I feel happy when I am working intensely $(A B 3)^{*}$

10. I I am proud on the work that I do (DE4)*

11. I I am immersed in my work $(A B 4)^{*}$

12. __ I can continue working for very long periods at a time (VI4)

13. To me, my job is challenging (DE5)

14. I I get carried away when I'm working $(A B 5)^{*}$

15. __ At my job, I am very resilient, mentally (VI5)

16. It is difficult to detach myself from my job (AB6)

17. __ At my work I always persevere, even when things do not go well (VI6)

* Shortened version (UWES-9); VI= vigor, DE = dedication; $\mathrm{AB}=$ absorption

6 Schaufeli \& Bakker (2003). The Utrecht Work Engagement Scale is free for use for non-commercial scientific research. Commercial and/or non-scientific use is prohibited, unless previous written permission is granted by the authors 


\section{Leadership Perceptions Survey}

Please answer the following questions based on your own perceptions about the Project Director and Program Manager within your region. There are no right or wrong answers. Your responses cannot be linked back to any personal information.

Please rate each statement on the following scale:

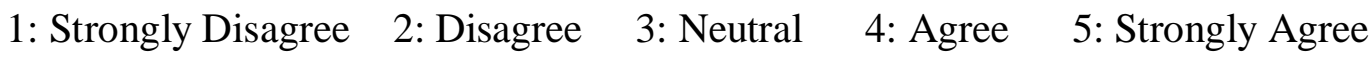

- When my leaders implement change, they care that the change is deep and longlasting.

a. Can you give an example of a time your leader demonstrated this behavior or a time when they demonstrated the opposite:

- If my leaders were to leave, my unit would experience a smooth transition to a new leader.

a. Can you give an example of a time your leader demonstrated this behavior or a time when they demonstrated the opposite:

- My leaders are thoughtful and deliberate in their actions.

a. Can you give an example of a time your leader demonstrated this behavior or a time when they demonstrated the opposite:

- My leaders consider what is right or just in their decision-making.

a. Can you give an example of a time your leader demonstrated this behavior or a time when they demonstrated the opposite:

- Diversity is a priority for my leader.

a. Can you give an example of a time your leader demonstrated this behavior or a time when they demonstrated the opposite:

- My leaders uses resources carefully.

a. Can you give an example of a time your leader demonstrated this behavior or a time when they demonstrated the opposite:

- My leader values the past.

a. Can you give an example of a time your leader demonstrated this behavior or a time when they demonstrated the opposite: 


\section{APPENDIX C}

Signed Gatekeeper Permission for Administrator and Educator Participation

Institutional Review Board Approval Letter 


\section{Gatekeeper Permission for Administrator and Educator Participation}

I, Jo Britt-Rankin, grant permission for administrators and educators within the Family Nutrition Education Programs to be contacted to participate in the study An Initial Examination of Sustainable Leadership and Employee Engagement within Extension Nutrition Programs conducted by Rachel Gordon-Poff, doctoral candidate at the University of Missouri.

By signing this permission form, I understand that the following safeguards are in place to protect faculty choosing to participate:

All participation is voluntary, and may be withdrawn at any point before culmination of the study.

All responses will be used for dissertation research and for potential future journal publications.

All identities will be kept confidential in all phases of the research.

An interview will occur with each administrator either in-person or via videoconference, lasting approximately one hour in length.

A survey to measure employee engagement will be sent to all FNEP educators using Qualtrics.

Please keep the consent letter and a copy of the signed consent form for your records. If you choose to grant permission for educators in your school district to participate in this study, please complete this Administrative Permission for Program Participation Form, please return it to Rachel Gordon-Poff as soon as possible.

I have read the material above, and any questions that I have posed have been answered to my satisfaction. I grant permission for administrators and educators in my program to be contacted and invited to participate in this study.

Signed: Jo Britt-Rankin

Date: $9 / 24 / 16$

Title/Position: Associate Dean/Program Director--HES Extension and Administrative Director/PI--FNEP

Institution: University of Missouri

Please return to: Rachel Gordon-Poff, 7903 Charlotte Street, Kansas City, MO 64131

Cell Phone: 816-213-2234 Email: gordonra@missouri.edu 
October 10, 2016

Principal Investigator: Rachel Louise Poff

Department: UW-Family Nutrition Program

Your Exempt Application to project entitled An Initial Examination of Sustainable Leadership and Employee Engagement within Extension Nutrition Programs was reviewed and approved by the MU Institutional Review Board according to the terms and conditions described below:

$\begin{array}{ll}\text { IRB Project Number } & 2006861 \\ \text { IRB Review Number } & 220150\end{array}$

Initial Application Approval Date October 10, 2016

IRB Expiration Date

October 10, 2017

Level of Review

Exempt

Project Status

Active - Open to Enrollment

Exempt Categories

45 CFR $46.101 b(2)$

Risk Level

Minimal Risk

Internal Funding

Personal funds

The principal investigator (PI) is responsible for all aspects and conduct of this study. The PI must comply with the following conditions of the approval:

1. No subjects may be involved in any study procedure prior to the IRB approval date or after the expiration date.

2. All unanticipated problems, adverse events, and deviations must be reported to the IRB within 5 days.

3. All changes must be IRB approved prior to implementation unless they are intended to reduce immediate risk.

4. All recruitment materials and methods must be approved by the IRB prior to being used.

5. The Annual Exempt Form must be submitted to the IRB for review and approval at least 30 days prior to the project expiration date. If the study is complete, the Completion/Withdrawal Form may be submitted in lieu of the Annual Exempt Form

6. Maintain all research records for a period of seven years from the project completion date.

7. Utilize all approved research documents located within the attached files section of eCompliance. These documents are highlighted green.

If you are offering subject payments and would like more information about research participant 
payments, please click here to view the MU Business Policy and Procedure: http://bppm.missouri.edu/chapter $2 / 2$ 250.html

If you have any questions, please contact the IRB at 573-882-3181 or irbømissouri.edu.

Thank you,

MU Institutional Review Board 


\section{VITA}

Rachel Gordon-Poff was born in Independence, MO and raised by her mother in Blue Springs, MO. Rachel received a Bachelor of Arts in English and Psychology from the University of Missouri-Columbia in 2008. She then completed a Master of Arts in Human Development and Family Studies in 2010 from the University of MissouriColumbia. She has spent her career in non-profit program management. She supervised a community mental health case management program. Then she coordinated the Family Nutrition Education Programs for the University of Missouri Extension in the Kansas City area. She managed a team of 25 paraprofessional educators who taught nutrition and physical activity education to a low-income audience. She served in this role for five years, including while obtaining the Doctorate of Educational Leadership from the University of Missouri-Columbia's Department of Education, Leadership, and Policy Analysis. She utilized the knowledge and skills through the EdD to help understand and improve the leadership practices being utilized by program leaders within FNEP at the University of Missouri Extension, as well as other federally funded nutrition education programs. Rachel currently works as a Vice President for W.A. Ellis Construction Co., and resides in Kansas City, MO with her husband. 